\title{
Epoxyeicosatrienoic acids protect cardiac cells during starvation by modulating an autophagic response
}

\author{
V Samokhvalov ${ }^{1,4}$, N Alsaleh ${ }^{1,4}$, HE El-Sikhry ${ }^{1}, \mathrm{KL}$ Jamieson ${ }^{1}$, CB Chen ${ }^{1}$, DG Lopaschuk ${ }^{1}$, C Carter ${ }^{2}$, PE Light ${ }^{2}$, R Manne ${ }^{3}$, \\ JR Falck ${ }^{3}$ and JM Seubert ${ }^{*, 1,2}$
}

Epoxyeicosatrienoic acids (EETs) are cytochrome P450 epoxygenase metabolites of arachidonic acid involved in regulating pathways promoting cellular protection. We have previously shown that EETs trigger a protective response limiting mitochondrial dysfunction and reducing cellular death. Considering it is unknown how EETs regulate cell death processes, the major focus of the current study was to investigate their role in the autophagic response of HL-1 cells and neonatal cardiomyocytes (NCMs) during starvation. We employed a dual-acting synthetic analog UA-8 (13-(3-propylureido)tridec-8-enoic acid), possessing both EET-mimetic and soluble epoxide hydrolase (sEH) inhibitory properties, or 14,15-EET as model EET molecules. We demonstrated that EETs significantly improved viability and recovery of starved cardiac cells, whereas they lowered cellular stress responses such as caspase-3 and proteasome activities. Furthermore, treatment with EETs resulted in preservation of mitochondrial functional activity in starved cells. The protective effects of EETs were abolished by autophagyrelated gene 7 (Atg7) short hairpin RNA (shRNA) or pharmacological inhibition of autophagy. Mechanistic evidence demonstrated that sarcolemmal ATP-sensitive potassium channels $\left(p m \mathrm{~K}_{\mathrm{ATP}}\right)$ and enhanced activation of AMP-activated protein kinase (AMPK) played a crucial role in the EET-mediated effect. Our data suggest that the protective effects of EETs involve regulating the autophagic response, which results in a healthier pool of mitochondria in the starved cardiac cells, thereby representing a novel mechanism of promoting survival of cardiac cells. Thus, we provide new evidence highlighting a central role of the autophagic response in linking EETs with promoting cell survival during deep metabolic stress such as starvation. Cell Death and Disease (2013) 4, e885; doi:10.1038/cddis.2013.418; published online 24 October 2013

Subject Category: Experimental Medicine

Cell turnover and homeostasis are tightly regulated processes that balance the demand to remove damaged cells and prevent widespread effects. Cells respond to stress by activating a variety of pathways enabling them to sense changes in their environment, such as starvation, hypoxia and mechanical damage. Dependent upon the extent and nature of the stressor, cells initiate responses that can promote either survival or death pathways. The molecular switches between these opposite responses involve a complex array of signals and adaptive pathways determining whether the cell will survive or die.

Arachidonic acid (AA) is a polyunsaturated fatty acid normally found esterified to cell membranes that can be released in response to several stimuli including ischemia and stress. ${ }^{1-3}$ Free AA can be metabolized by cytochrome $P 450$ epoxygenases to epoxyeicosatrienoic acids (EETs) that are further metabolized to dihydroxyeicosatrienoic acids (DHETs) (via soluble epoxide hydrolase $(\mathrm{sEH}))$ or incorporated into membranes., ${ }^{4,5}$ EETs are lipid mediators that act as potent cellular signaling molecules regulating key cellular processes, such as limiting mitochondrial damage, inhibiting apoptosis and reducing inflammatory responses. ${ }^{6-9}$ Despite extensive research efforts investigating the biological effects of EETs, their intrinsic mechanism(s) of action remains poorly understood. ${ }^{10}$ Although there is no known EET receptor, evidence demonstrates that they act as intracellular signaling molecules affecting proteins such as cardiac ATP. sensitive potassium channels $\left(p m K_{\mathrm{ATP}}\right) .{ }^{11-13}$ Moreover, EET-mediated signaling has a role in cancer progression by stimulating cell proliferation, survival, migration and invasion. $^{14}$

\footnotetext{
${ }^{1}$ Faculty of Pharmacy and Pharmaceutical Sciences, University of Alberta, Edmonton, Alberta, Canada; ${ }^{2}$ Department of Pharmacology, Faculty of Medicine, University of Alberta, Edmonton, Alberta, Canada and ${ }^{3}$ Departments of Biochemistry and Pharmacology, University of Texas Southwestern Medical Center, Dallas, TX, USA ${ }^{*}$ Corresponding author: JM Seubert, University of Alberta, Faculty of Pharmacy and Pharmaceutical Sciences, 2020-M Katz Group Centre for Pharmacy and Health Research, 11361-97 Avenue, Edmonton, Alberta T6G 2E1, Canada. Tel: +1 780492 0007; Fax: +1 780492 1217; E-mail: jseubert@ualberta.ca

${ }^{4}$ These authors contributed equally to this work.

Keywords: autophagy; epoxyeicosatrienoic acid; cardiac cells

Abbreviations: 14,15-EEZE, 14,15-epoxyeicosa-5(Z)-enoic acid; 3-MA, 3-methyladenine; AA, Arachidonic acid; AMC, 7-amino-4-methylcoumarin; AMPK, AMP-activated protein kinase; Atg7, autophagy-related gene 7; CaMKK $\beta, \mathrm{Ca}^{2+}$ calmodulin-dependent protein kinase kinase- $\beta$; CFA, colony formation ability; COX IV, cytochrome coxidase; CS, citrate synthase; DHET, dihydroxyeicosatrienoic acid; DMSO, dimethyl sulfoxide; EETs, epoxyeicosatrienoic acid; FBS, fetal bovine serum; GFP, green fluorescent protein; LC3, microtubule-associated protein light chain 3; LDH, lactate dehydrogenase; mTORC1, mammalian target of rapamycin complex 1; MTT, 3-[4,5-dimethylthiazol-2-yl]-2,5-diphenyl tetrazolium bromide; NCM, neonatal cardiomyocyte; PBS, phosphate buffer saline; PCG-1 $\alpha$, PPAR- $\gamma$ coactivator- $1 \alpha ; m_{\text {ATP }}$, cardiac ATP-sensitive potassium channels; $\mathrm{SDH}$, succinate dehydrogenase; sEH, soluble epoxide hydrolase; shRNA, short hairpin RNA; tAUCB, trans-4-[4-(3-adamantan-1-y1-ureido)-cyclohexyloxy]-benzoic acid; UA-8, 13-(3-propylureido)tridec-8-enoic acid; ULK1, UNC-51-like kinase; VDAC, voltage-dependent anion channel
}

Received 22.5.13; revised 21.9.13; accepted 26.9.13; Edited by GM Fimia 
The fate of the cell depends on the intensity of cellular stress and activation of specific survival mechanism(s). Predominance of one pathway over another, such as autophagy over apoptosis, results in cell survival or death. Autophagy represents an evolutionarily conserved catabolic process in which intracellular macromolecules and organelles are sequestered in autophagosomes for recycling. ${ }^{15}$ Autophagy plays an essential role in cellular response to stress and is an important survival mechanism of terminally differentiated cells such as cardiomyocytes. ${ }^{16-19}$ It has been suggested that resistance of cells to environmental stress factors, including starvation, vastly depends on their ability to activate compensatory reactions, providing rapid turnover of damaged molecules and entire organelles such as mitochondria. ${ }^{20,21}$ Preservation of mitochondrial integrity by autophagy represents a biologically beneficial strategy as preserved mitochondria can greatly contribute to prolonging cell survival. ${ }^{22,23}$ Stressed cells solely rely on the coordination of multiple response pathways that are controlled at the molecular level by a number of highly conserved molecules, such as AMP-activated protein kinase (AMPK). AMPK acts as an intracellular sensor of energy status that is activated by an increase in the intracellular AMP/ATP ratio, including response to metabolic stress observed in starvation. ${ }^{24}$ Once activated, AMPK switches on catabolic pathways that generate ATP while switching off ATP-consuming processes, such as cell growth and proliferation, and activating autophagy. ${ }^{25}$ Other critical molecules like pmK $_{\text {ATP }}$ channels are involved in the cellular response by regulating ionic homeostasis under conditions of metabolic stress; although these channels have demonstrated cardioprotective effects, their role in regulating cell death pathways is limited. ${ }^{26}$ Excessive injury of cardiomyocytes in the heart results in collapse of cardiac function. Therefore, unraveling the mechanisms that regulate the balance between autophagic-mediated cellular survival and apoptosis-associated cell death will further our understanding of the cardiovascular system.

Our understanding of EET involvement in regulating cell death and survival pathways is limited to their antiapoptotic effect; moreover, nothing is known regarding EET regulation of autophagy. ${ }^{27}$ Modulating cellular survival mechanisms, such as autophagy, by EETs can provide new insight in understanding cardiovascular biology. In order to address this aspect, we examined the protective effects of EETs on starved cardiac cells. In this study, we demonstrated that EETs modulate the autophagic response in starved cardiac cells through mechanisms involving pmK $_{\text {ATP }}$ channels and AMPK. Consequently, the EET-mediated response protected mitochondrial function that resulted in a healthier mitochondrial pool and increased viability of the starved cardiac cells. Thus, we report a novel EET-mediated protective mechanism for cardiac cell survival during starvation.

\section{Results}

UA-8 preserved viability and functional activity of HL-1 cardiac cells during starvation. The protective effect of 13-(3-propylureido)tridec-8-enoic acid (UA-8) was evaluated using Trypan blue exclusion that reflects loss of cell membrane integrity and cell death. Figure 1a demonstrates the dynamics of cell death during starvation. Starvation induced significant cell death in control groups that progressively increased over time. After $48 \mathrm{~h},>75 \%$ of control cells were dead. Protection of cell viability conferred by UA-8 was observed for up to $48 \mathrm{~h}$ of starvation. In contrast, cotreatment with 14,15-EEZE (14,15-epoxyeicosa-5(Z)-enoic acid), an EET antagonist, abolished the protective effects of UA-8, whereas 14,15-EEZE treatment alone had an even greater rate of cell death as compared with the control.

In our model of starvation, we also employed an alternative test of cell viability based on accumulation of the reduced form of MTT (3-[4,5-dimethylthiazol-2-yl]-2,5-diphenyl tetrazolium bromide) in mitochondria, which reflects the ability of cells to maintain oxidative metabolic activity. ${ }^{28}$ Starvation induced a robust accumulation of formazan in $\mathrm{HL}-1$ cells within $24 \mathrm{~h}$ in all experimental groups, except UA-8, suggesting that a rapid activation of mitochondrial metabolic activity was initiated to provide energy for cell survival in response to starvation (Figure 1b). The initial activation subsided with a dramatic decline in cellular metabolism. Treatment with UA-8 significantly delayed the metabolic collapse of starved HL-1 cells. Cotreatment with 14,15-EEZE abolished the protective effect of UA-8.

The ability of cells to recover from stress and form new colonies is an evolutionary mechanism involved in survival and expansion. We measured the ability of $\mathrm{HL}-1$ cells to form colonies after $24 \mathrm{~h}$ of starvation by employing a crystal violetbased test. We observed that only $15 \%$ of cells derived from control groups were able to recover and form colonies, whereas $35 \%$ of UA-8 treated HL-1 cells were able to recover (Figure 1c). The protective effect of UA-8 was attenuated by cotreatment with 14,15-EEZE. Collectively, these findings demonstrate that treatment with UA-8 significantly enhances viability of $\mathrm{HL}-1$ cells during starvation, allowing cells to recover from injury. Further evidence of protection was observed following $24 \mathrm{~h}$ of starvation where $\mathrm{HL}-1$ cells treated with UA-8 were still beating, indicating retention of functional activity (Figure 1d).

UA-8 ameliorates the detrimental effects of starvation. Starvation is known to initiate a very complex, yet poorly understood, stress response. Therefore, we focused on unraveling the possible mechanisms involved in cell death during starvation and whether UA-8 could affect the cell death process. Accordingly, we estimated alterations in caspase- 3 and proteasomal activities in $\mathrm{HL}-1$ cells during

Figure 1 Survival and functional activity of $\mathrm{HL}-1$ cardiac cells during $48 \mathrm{~h}$ of starvation. $\mathrm{HL}-1$ cells were treated with $\mathrm{UA}-8(1 \mu \mathrm{M})$ in the presence or absence of $14,15-\mathrm{EEZE}$ $(10 \mu \mathrm{M})$ in amino acid-free and serum-free starvation buffer. (a) Cell viability was assessed by Trypan blue exclusion. (b) Total mitochondrial activity was measured by MTT assay. (c) Alterations in colony formation ability of $\mathrm{HL}-1$ cells starved for $24 \mathrm{~h}$ with and without UA-8. (d) Effect of UA-8 on contractility of $\mathrm{HL}-1 \mathrm{cells}$ starved for $24 \mathrm{~h}$ (e) Changes in caspase-3 activity of HL-1 cells starved with and without UA-8. (f) Changes in total proteasome activity of HL-1 cells starved with and without UA-8. (g) Effect of UA-8 on total antioxidant capacity of $\mathrm{HL}-1$ cells starved for $24 \mathrm{~h}$. Values are represented as mean \pm S.E.M., $N=3$. Significance was set at $P<0.05$, *significantly different from control nonstarvation or statistically not different (ND), " significantly different from UA-8 

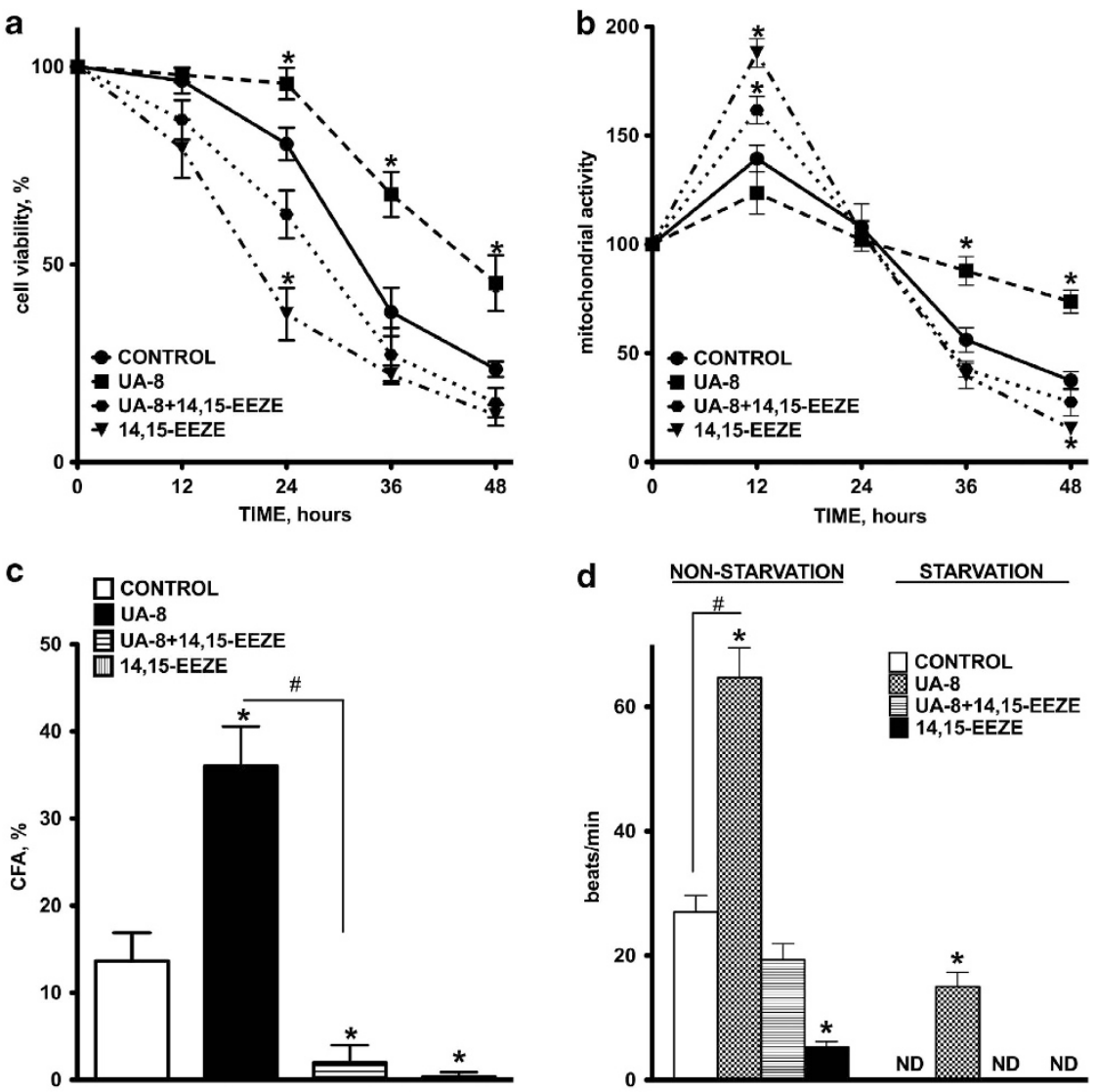

d NON-STARVATION STARVATION
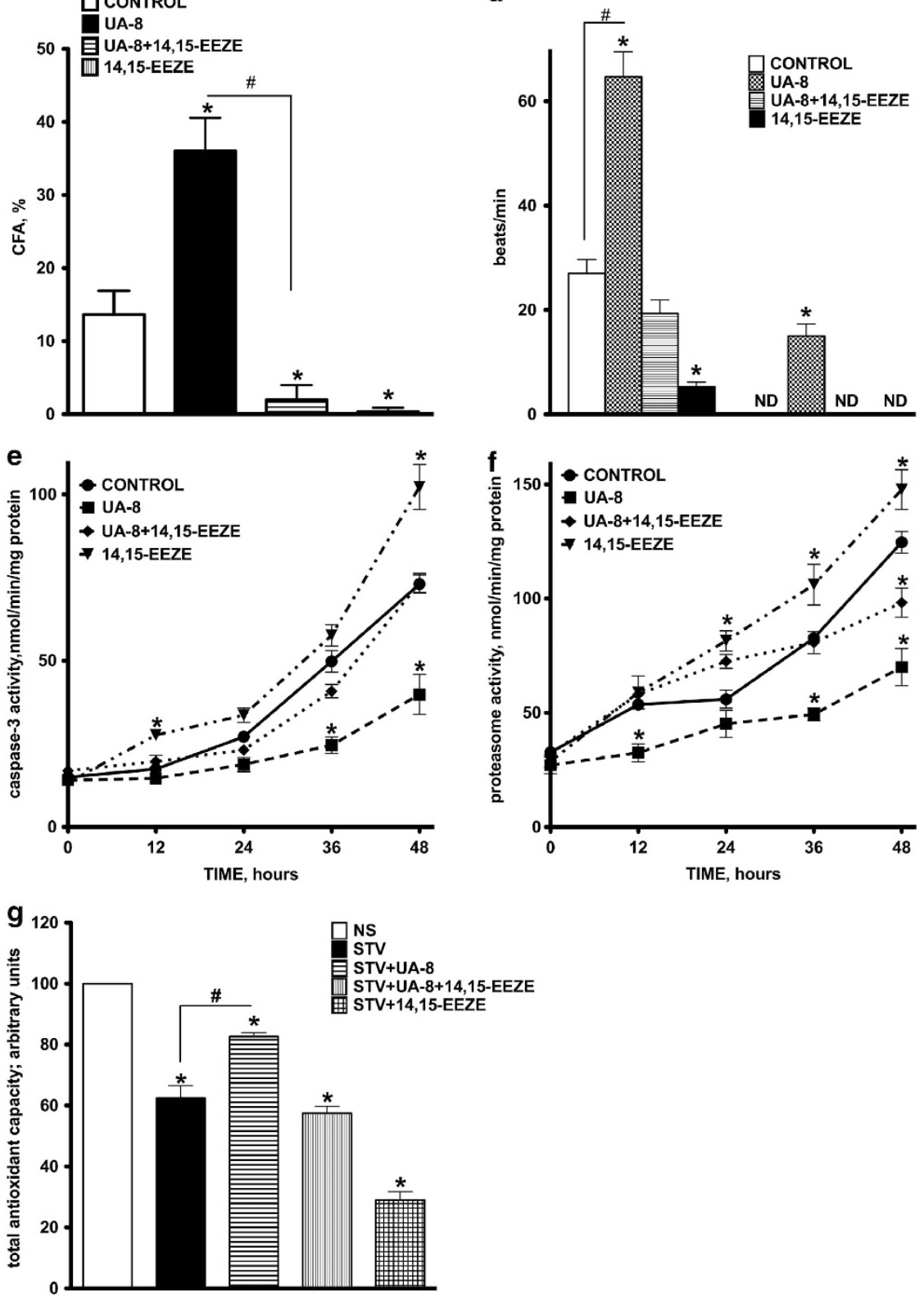
starvation to assess overall cellular injury. Starvation is known to trigger release of apoptogenic factors inducing cell death. Thus, we determined the apoptotic response in starvation-induced cell death. We observed that starvation induced a rapid activation of caspase-3, indicating apoptotic response, that was significantly attenuated when cells were treated with UA-8 (Figure 1e).

Following extended starvation, cells begin to catabolize various complex molecules such as polysaccharides, nucleic acids and proteins to provide substrates for energy production. The accumulation of ubiquinated proteins followed by activation of $20 \mathrm{~S}$ proteasome activity represents a marker of this cellular degenerative process. ${ }^{29}$ We therefore assessed $20 \mathrm{~S}$ proteasome activity in starved HL-1 cells. Starvation induced a rapid increase in the level of 205 proteasome activity in $\mathrm{HL}-1$ cells that was significantly attenuated when cells were treated with UA-8 (Figure 1f). Starvation induced a collapse of the cellular total antioxidant capacity in control as compared with UA-8-treated cells, suggesting that UA-8 either limited the activation of ROS generation and oxidative stress or preserved the antioxidant defense (Figure 1g). Together, the data demonstrate that UA-8 has a strong antidegenerative effect toward starved cells. All protective effects of UA-8 were greatly diminished by cotreatment with 14,15-EEZE, suggesting an intrinsic EET-mediated mechanism.

Treatment with UA-8 prevented starvation-induced cellular stress responses in NCMs. We subjected neonatal cardiomyocytes (NCMs) to $24 \mathrm{~h}$ of starvation following the same protocol as used for $\mathrm{HL}-1$ cells. Starvation triggered activation of both caspase-3 (Figure 2a) and proteasome activities in NCMs (Figure 2b), and significantly reduced beating rate (Figure $2 \mathrm{c}$ ) and total antioxidant capacity (Figure 2d). Consistent with the data observed in $\mathrm{HL}-1$ cells, treating NCMs with UA-8 significantly reduced the adverse responses triggered by starvation. Importantly, cotreatment with 14,15-EEZE abolished the protective effects of UA-8.

UA-8 modulates the autophagic response in starved HL-1 cells. Cell survival during starvation has been shown to activate autophagy that represents a major pathway in recycling amino acids and removing damaged organelles. ${ }^{30}$ In accordance with this concept, it was reasonable to suggest that regulation of autophagy might represent an integral component of the UA-8 protective effect toward HL-1 cells
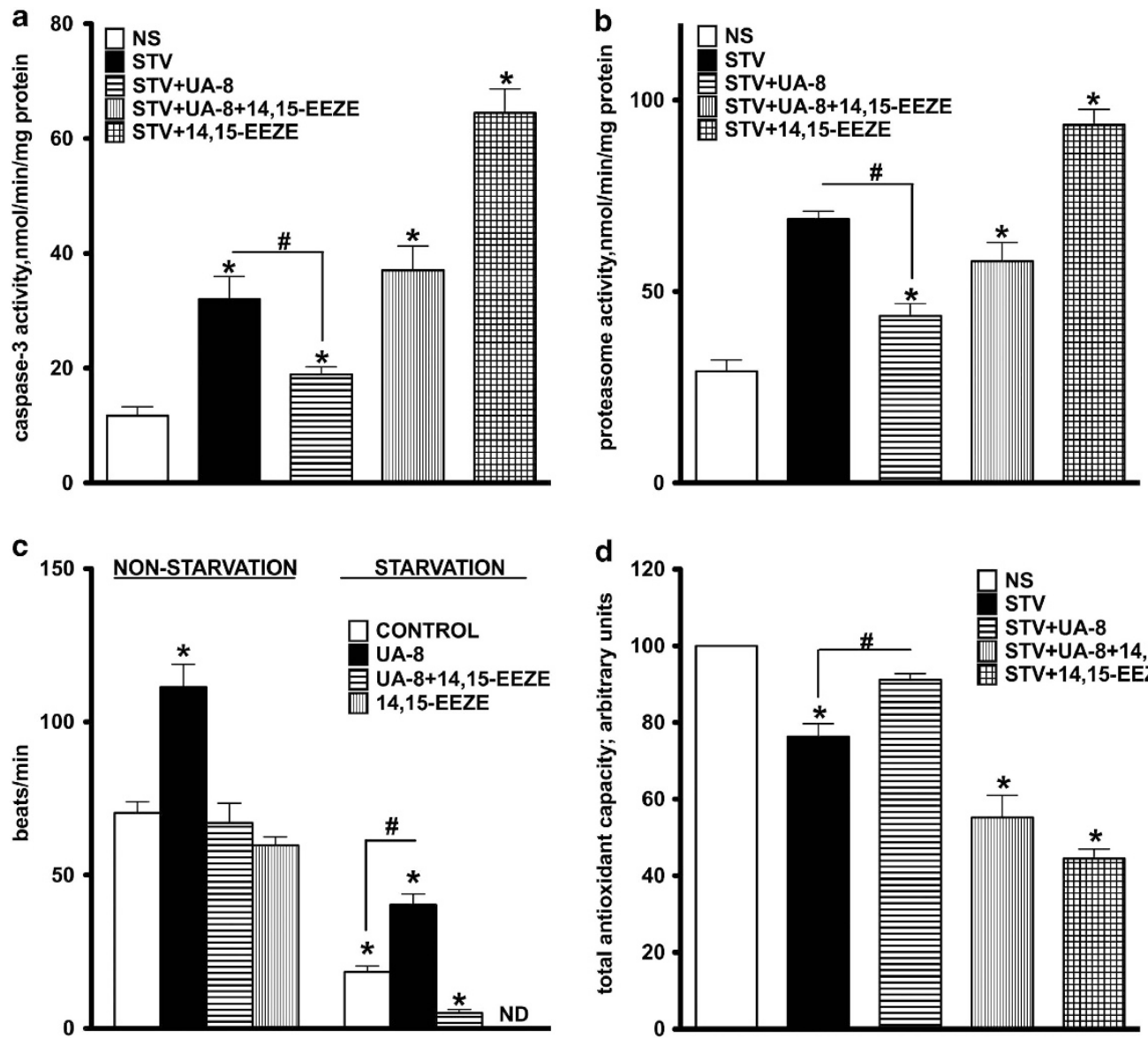

Figure 2 Effect of UA-8 treatment on starvation-induced cellular stress responses in NCMs. NCMs were treated with UA-8 $(1 \mu \mathrm{M})$ in the presence or absence of 14 , 15 -EEZE $(10 \mu \mathrm{M})$ in amino acid-free and serum-free starvation buffer for $24 \mathrm{~h}$. Starvation induced activation of caspase-3 (a) and proteasome activity (b) in NCMs. (c) UA-8 potentiated the beating rate of nonstarved (NS) NCMs and prevented starvation-induced decline of the beating rate in starved (STV) NCMs. (d) Alterations in total antioxidant capacity of NCMs exposed to starvation for $24 \mathrm{~h}$ with and without UA-8. Cotreatment with 14,15-EEZE antagonized the effect of UA-8. Values are represented as mean \pm S.E.M., $N=3$. Significance was set at $P<0.05$, "significantly different from control nonstarvation or statistically not different (ND), " significantly different from UA-8 
during starvation. To our knowledge, no data have been published regarding the effect of eicosanoids on regulation of autophagy. Therefore, we assessed the level of autophagy in starved HL-1 cells. The formation of microtubule-associated protein light chain 3-II (LC3-II) protein and assembling of autophagosomes are important steps in the autophagic pathway. Figure $3 a$ demonstrates that starvation rapidly upregulated the levels of LC3-II in HL-1 cells during the first $2 \mathrm{~h}$ of starvation, followed by a slow decline until the end of starvation. Remarkably, treatment with UA-8 resulted in a constantly higher level of LC3-II expression in starved cells. Figure $3 a$ shows results of western blot quantification after 2 and $24 \mathrm{~h}$ of starvation, demonstrating a fivefold increase in LC3-II expression in HL-1 cells treated with UA-8 during starvation. Furthermore, cotreatment with 14,15-EEZE significantly prevented UA-8-mediated effects on the autophagic response.

LC3-II has a crucial role in the formation of autophagosomes, which are subsequently targeted to lysosomes. An individual autophagosome is represented as a punctum by immunofluorescence microscopy. Autophagy is a dynamic process that involves a continual flux in healthy cells. Chloroquine is known to prevent the degradation of autophagosomes, resulting in their accumulation within the cell. Chloroquine was used as a control treatment to demonstrate morphological hallmarks of autophagosomes. Treatment of $\mathrm{HL}-1$ cells with chloroquine significantly increased the number of autophagosomes, whereas control cells had only a few puncta and very disperse intracellular fluorescence. Starvation triggered accumulation of autophagosomes in $\mathrm{HL}-1$ cells (Figure 3b). Importantly, we observed that the formation of autophagosomes was robust and appeared merged in the cells treated with UA-8. There was a noticeable reduction in intracellular fluorescence as compared with starvation control. Cotreatment with 14,15-EEZE attenuated the formation of autophagosomes in starved $\mathrm{HL}-1$ cells treated with UA-8. Together, these data suggest that UA-8 treatment results in formation of LC3-II and accumulation of autophagosomes. Further evidence observed in electron micrograph images revealed autophagosomal bodies in $\mathrm{HL}-1$ cells following $24 \mathrm{~h}$ of starvation and UA-8 treatment, with some vacuoles containing mitochondria (Figure 3c). Nonvacuolized mitochondria were dense and contained compact cristae correlating with increased function. Mechanistically, it is possible that UA-8 might be blocking the autophagic flux in starved cells. However, given the fact that autophagy represents a mechanism of cell survival during starvation, we hypothesize that the protective effects of UA-8 enhanced the autophagic response.

14,15-EET limits starvation-induced injury. To assess whether the protective effects of UA-8, a structural analog of EET with sEH inhibition properties, resembles those of EETs, we assessed the effect of 14,15-EET with and without 14,15EEZE following $24 \mathrm{~h}$ of starvation in $\mathrm{HL}-1$ cells and in NCMs. ${ }^{31}$ Similar to UA-8, 14,15-EET increased the levels of LC3-II in both HL-1 cells (Figure 4a) and NCMs (Figure 4b) after $24 \mathrm{~h}$ of starvation, suggesting there was activation of the autophagic response. Furthermore, treatment with 14 15-EET attenuated starvation-increased caspase-3 and proteasome activities in $\mathrm{HL}-1$ cells (Figure 4c) and NCMs (Figure 4d). Importantly, addition of 14,15-EEZE abolished all protective effects of 14,15-EET as observed with UA-8.

UA-8 protects mitochondria function. In order to sustain cell viability and recover from injury, cellular responses to stress include steps that attempt to preserve mitochondrial integrity. ${ }^{22}$ To determine the impact of starvation on mitochondrial function, we assessed the activities of key enzymes reflecting the state of mitochondrial metabolic activity. ${ }^{23}$ We found that UA-8 prevented the decrease in citrate synthase, succinate dehydrogenase and COX IV enzymatic activities observed in control groups following $24 \mathrm{~h}$ of starvation; no significant protective effect was observed for $\mathrm{SDH}$ in $\mathrm{HL}-1$ cells (Figures $5 \mathrm{a}-\mathrm{f}$ ). Next, we assessed western blot to detect alterations in the expression of essential mitochondrial proteins during starvation. We found that NCMs starved for $24 \mathrm{~h}$ had an elevated level of mitochondrial marker proteins such as VIDAC, SDH and COX IV (Figures $5 \mathrm{~g}-\mathrm{i})$. This observation suggests that starved cardiac cells did not lose mitochondrial content. This observation is also reinforced by EM images (Figure 3c) where preservation of mitochondrial content during starvation is clearly demonstrated.

UA-8 protective effect modulates the autophagic response. In order to more precisely clarify the involvement of autophagy in the UA-8-mediated protective effect, we infected $\mathrm{HL}-1$ cells with short hairpin RNA (shRNA) targeted to autophagy-related gene 7 (Atg7) or nonspecific shRNA (SHAM). Atg7 is an essential protein for autophagosomal formation. ${ }^{32}$ Silencing $A t g 7$ resulted in a significant decline in cell viability during starvation, where $>80 \%$ of cells were dead at $24 \mathrm{~h}$ and were no longer protected by UA-8 (Figures $6 \mathrm{a}$ and $\mathrm{b}$ ). Similar results were observed when caspase-3 (Figure 6c) and proteasome activities were assessed (Figure 6d). Atg7-silencing resulted in robust activation of both caspase-3 and proteasome activities in HL-1 cells after $12 \mathrm{~h}$ of starvation, which UA-8 failed to inhibit. In addition, Atg7-silencing significantly decreased LC3-II protein levels (Figure 6e), suggesting autophagy was inhibited.

In order to further reinforce the outcome of Atg7-silencing experiments, we inhibited autophagy in $\mathrm{HL}-1$ cells by using the pharmacological agent, 3-methyladenine (3-MA), which prevents formation of autophagosomes in mammalian cells. ${ }^{32}$ Figures $6 f$ and $g$ show that treatment with 3-MA $(5 \mathrm{mM} / \mathrm{l})$ within $24 \mathrm{~h}$ abolished the UA-8-mediated inhibition of caspase-3 and total proteasome activities in starved HL-1 cells. Consistent with the above observations, our data suggest that modulation of autophagy is an important component of UA-8 protective effects during starvation.

\section{UA-8 protective effect is mediated by ATP-sensitive $\mathbf{K}^{+}$} channels. Cardiac $p m K_{\text {ATP }}$ channels are involved in regulating ionic homeostasis under conditions of metabolic stress and have demonstrated cardioprotective effects toward ischemia-reperfusion injury. ${ }^{26,33}$ EETs have been shown to be activators of pmK $\mathrm{K}_{\mathrm{ATP}}$ channels affecting mitochondrial function. ${ }^{11,13}$ To determine whether UA-8mediated effects occur via pmK $\mathrm{K}_{\mathrm{ATP}}$ channels, both $\mathrm{HL}-1$ 
a

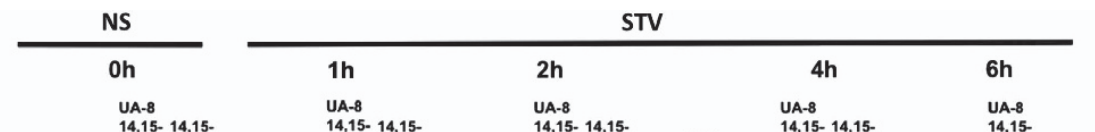

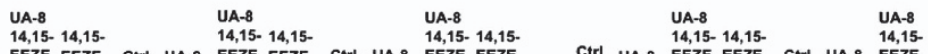
\begin{tabular}{llll} 
Ctrl UA-8 EEZE EEZE Ctrl UA-8 EEZE EEZE Ctrl UA-8 EEZE EEZE & $\begin{array}{l}14,15-14,15- \\
\text { Ctrl UA-8 EEZE EEZE }\end{array}$ Ctri UA-8 EEZE \\
\hline
\end{tabular}

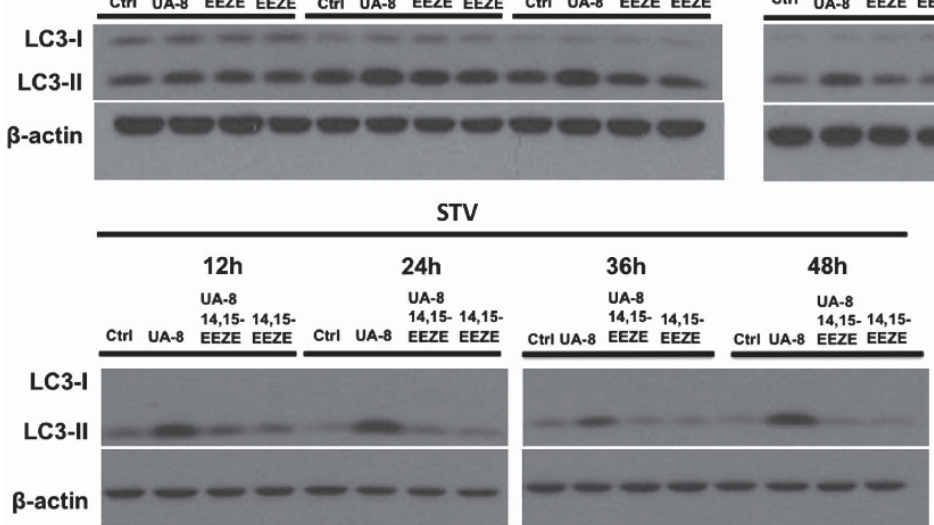

b

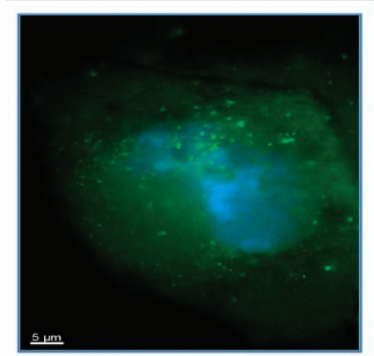

control
NS

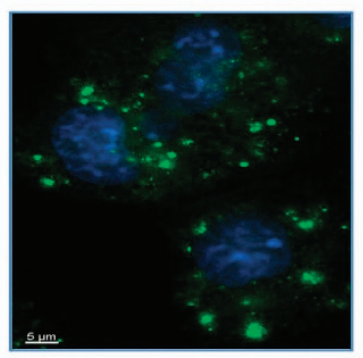

CIQ

STV

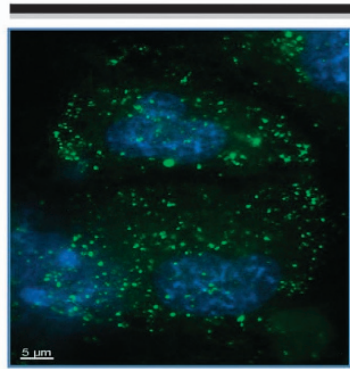

control

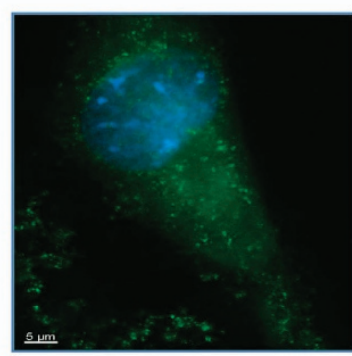

UA-8+14,15-EEZE

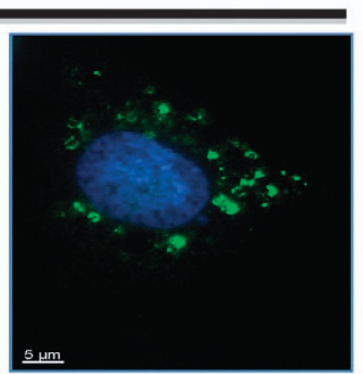

UA-8

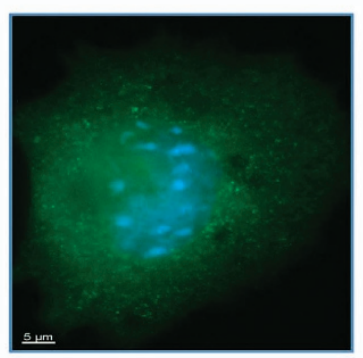

14,15-EEZE

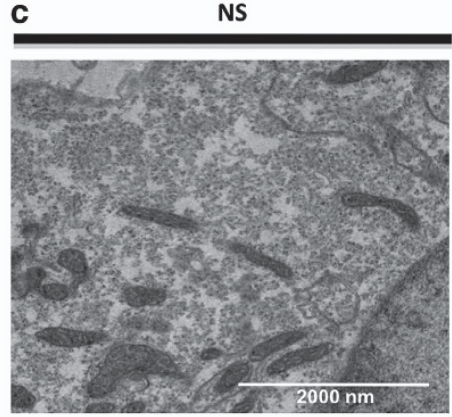

control

STV

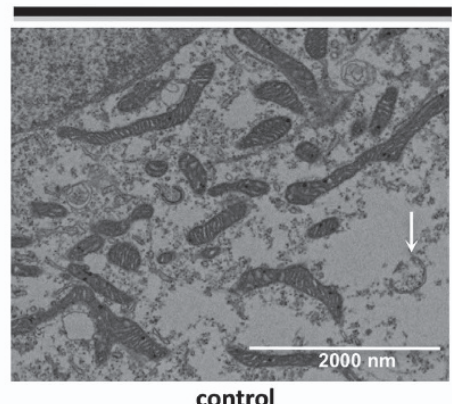

control

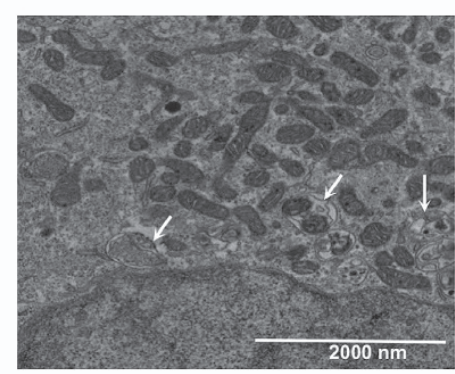

UA-8

Figure 3 Treatment with UA-8 modulates the autophagic response in HL-1 cells during starvation. (a) Formation of LC3-II protein in starved HL-1 cells. Left panel: representative western blots demonstrating the time course accumulation of LC3-II in starved cells. Right panel shows the results of western blot quantification after 2 and $24 \mathrm{~h}$ of starvation, respectively. (b) Representative images following $24 \mathrm{~h}$ of starvation in $\mathrm{HL}-1$ cells immunostained to detect LC3 positive puncta (green), a marker of autophagy. Nonstarved HL-1 cells were treated with chloroquine $(50 \mu \mathrm{M})$, a blocker of autophagosomal degradation, as a control. Images were acquired with a Zeiss Axio Observer epifluorescence microscope using a $\times 63$ objective (Oberkochen, Germany). Alexa Fluor 488 was conjugated LC3 Ab (green) and DAPI nuclear stain (blue) were utilized. (c) Representative electron micrograph (EM) images of nonstarved $\mathrm{HL}-1$ cells and cells starved for $24 \mathrm{~h}$ with and without UA-8. White arrows identify autophagosomal vacuoles; note mitochondrial engulfment. Values are represented as mean \pm S.E.M., $N=3$. Significance was $P<0.05$, *significantly different from control nonstarvation, "significantly different from UA-8 
a
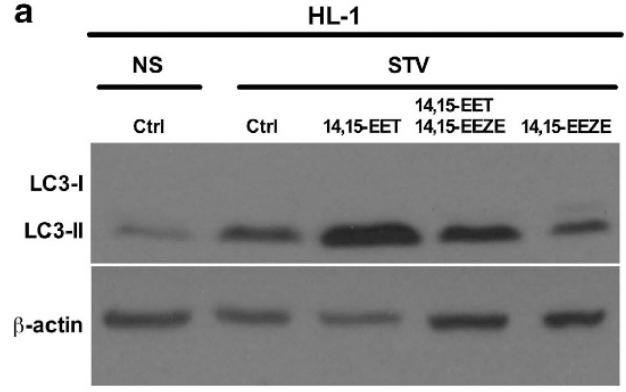

ST

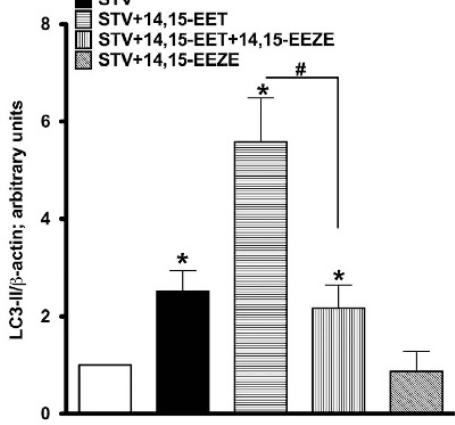

C

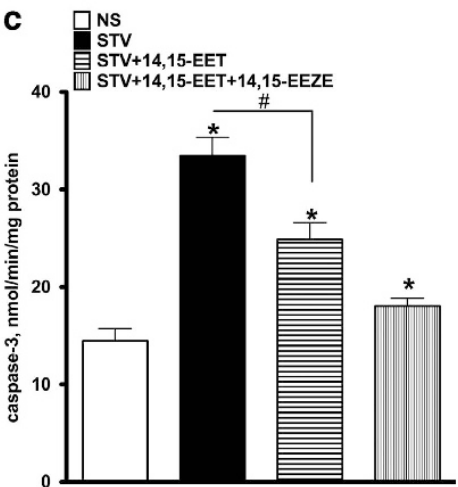

b
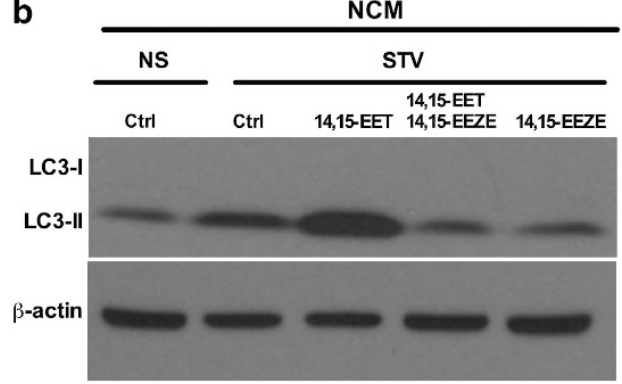

NS
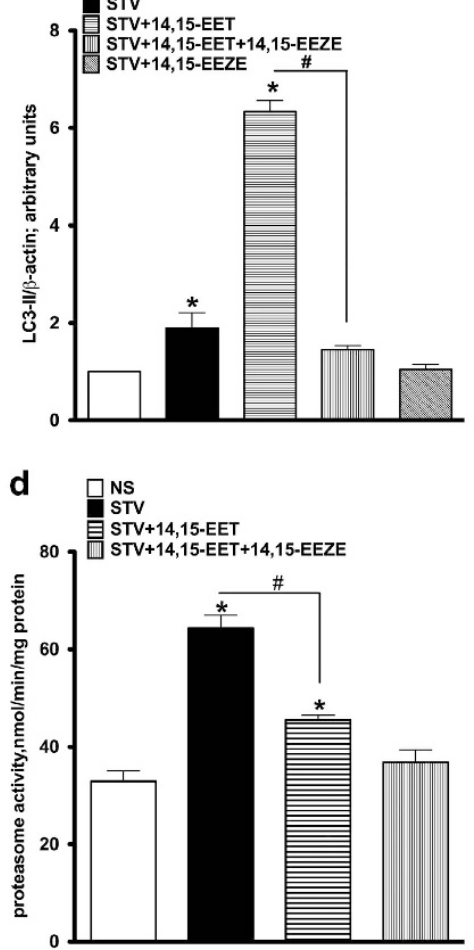

Figure 4 Treatment with 14,15-EET recapitulated the protective effects of UA-8 toward starved HL-1 cells and NCMs. HL-1 cells and NCMs were starved for $24 \mathrm{~h}$ with or without 14,15-EET $(1 \mu \mathrm{M})$. Treatment with 14,15-EET increased the levels of LC3-II in starved HL-1 cells (a) and in NCMs (b) as demonstrated in immunoblots and quantified in corresponding histograms. Treatment with 14,15-EET attenuated starvation-induced caspase-3 (c) and proteasome activities (d) in starved HL-1 cells. Cotreatment with 14,14-EEZE $(10 \mu \mathrm{M})$ abolished all observed protective effects of 14,15 -EET. Values are represented as mean \pm S.E.M., $N=3$. Significance was $P<0.05$, ${ }^{*}$ significantly different from control nonstarvation, " significantly different from 14,15-EET

cells and NCMs were treated with HMR-1098 $(10 \mu \mathrm{M})$, a pmK $\mathrm{K}_{\mathrm{ATP}}$ channel selective inhibitor, under starvation conditions for $24 \mathrm{~h}$ (Figure 7 ). Inhibition of $p m \mathrm{~K}_{\mathrm{ATP}}$ channels with HMR-1098 prevented UA-8-mediated cellular protection against starvation-induced injury in $\mathrm{HL}-1$ cells, resulting in increased lactate dehydrogenase (LDH) release, proteasome and caspase- 3 activities and decreased beating rate (Figures 7a-d). Consistent with the response in $\mathrm{HL}-1$ cells, we observed that inhibition of $p m K_{\mathrm{ATP}}$ channels resulted in a significant loss of UA-8 protective effects in NCMs during starvation (Figures 7e-h).

Activation of AMPK and modulation of the autophagic response in starved cells by UA-8 was abolished by co-treatment with HMR-1098. AMPK is a key metabolic sensor strongly activated under conditions of nutrient deprivation, such as during ischemia, that has a role in regulating cell proliferation and cell death. In both $\mathrm{HL}-1$ cells and NCMs, treatment with UA-8 resulted in a significant increase in phosphorylated AMPK following $24 \mathrm{~h}$ of starvation. This correlated with a marked increase in LC3-II levels (Figures $8 \mathrm{a}$ and b). Importantly, inhibition of $p m \mathrm{~K}_{\mathrm{ATP}}$ channels with HMR-1098 abolished the UA-8-mediated activation of AMPK and increase in the levels of LC3-II (Figure 8).

\section{Discussion}

In this study, we demonstrated that EET-mediated events protect cardiac cells during starvation. The protective effect reduced proteasomal and caspase-3 activities, which significantly improved cell viability and recovery of starved cardiac cells. Interestingly, the protective effect involved modulating the autophagic response, thus shifting the cell 
HL-1
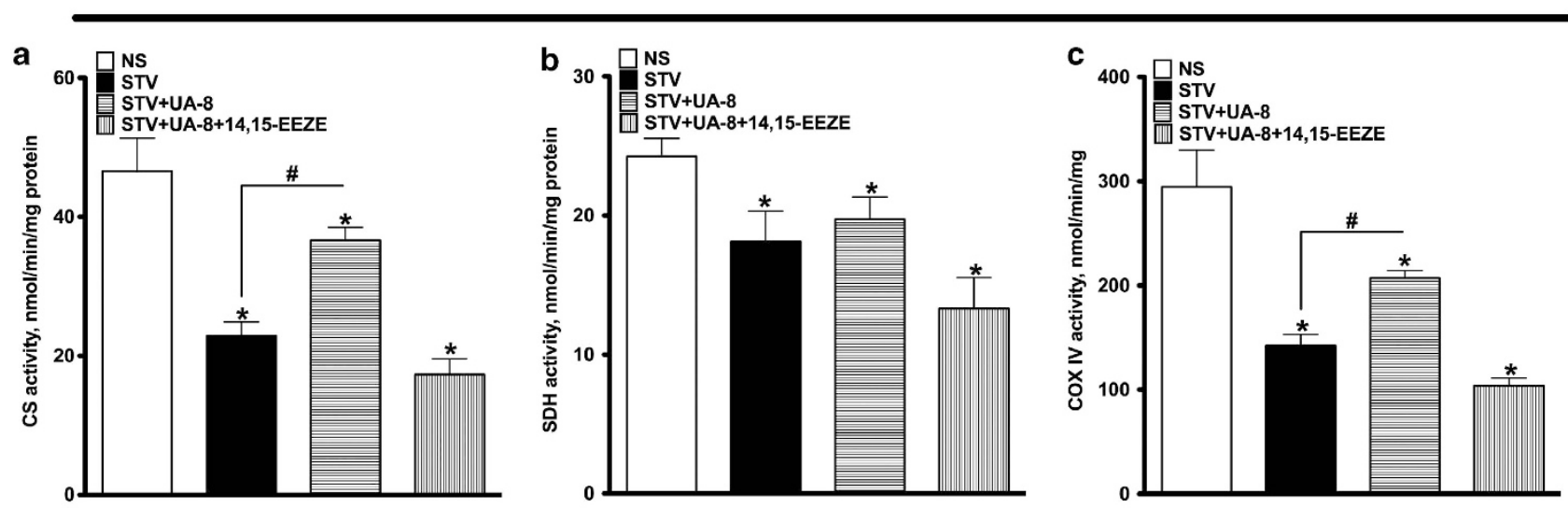

NCM
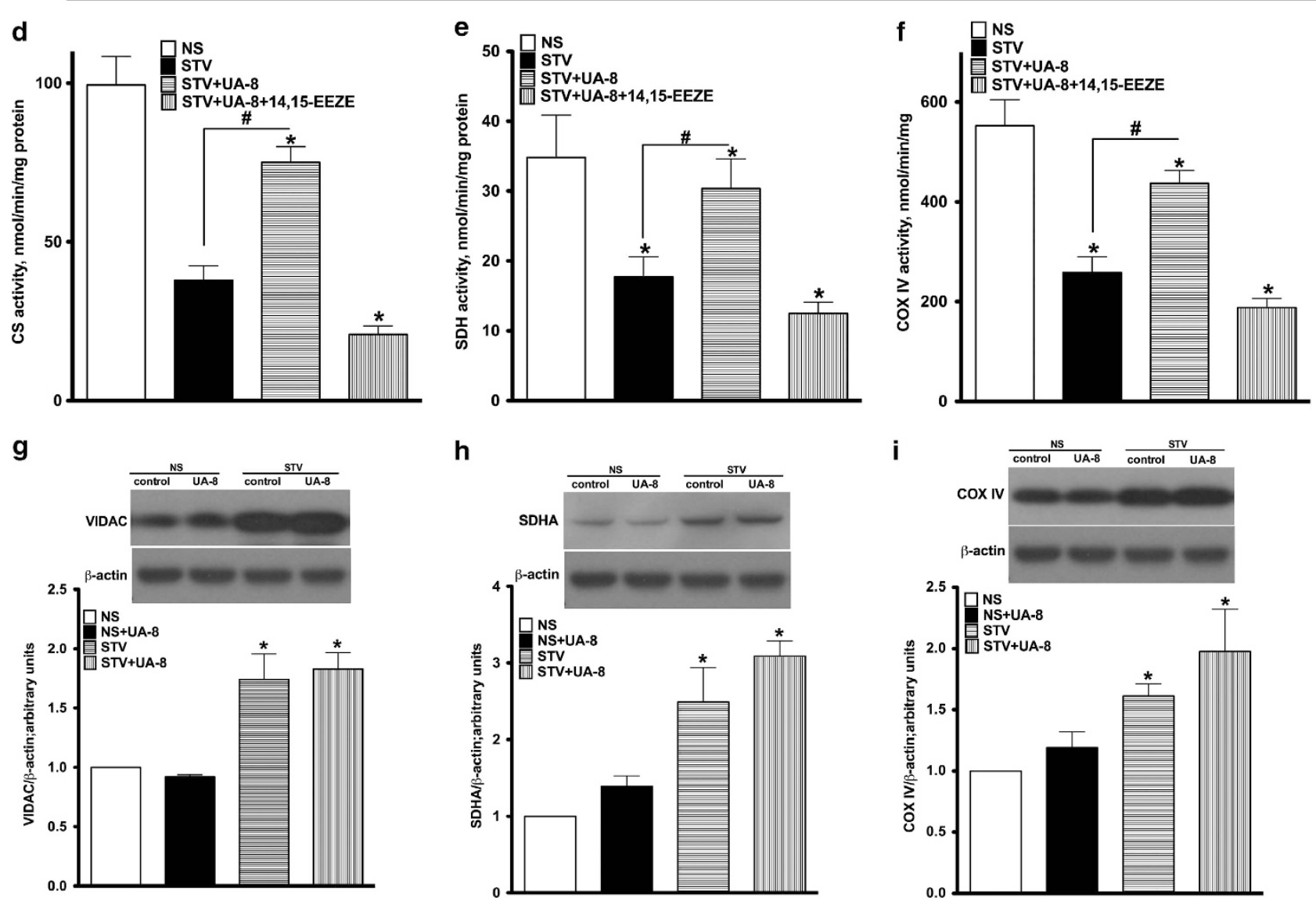

Figure 5 Treatment with UA-8 preserves a healthy pool of mitochondria during starvation. Activities of key mitochondrial enzymes were assessed in HL-1 cells and NCMs following $24 \mathrm{~h}$ of starvation. Citrate synthase $(\mathbf{a}, \mathbf{d})$, succinate dehydrogenase $(\mathbf{b}, \mathbf{e})$ and COX IV $(\mathbf{c}, \mathbf{f})$ activities were measured in HL-1 cells and NCMs in nonstarved (NS) and starved cells (24 h STV) treated with UA-8 $(1 \mu \mathrm{M})$ or without 14,15-EEZE $(10 \mu \mathrm{M})$. Increased expression of mitochondrial proteins (g) VDAC, (h) succinate dehydrogenase and (i) COX IV in NCMs following $24 \mathrm{~h}$ of starvation were observed in both control and UA-8-treated cells, as detected by western blot. Values are represented as mean \pm S.E.M., $N=3$. Significance was $P<0.05$, *significantly different from control nonstarvation, ${ }^{\#}$ significantly different from UA-8

death process to promote cell survival. Mechanistic data suggested that the signaling pathway involved pmK $_{\text {ATP }}$ channels and activation of AMPK in starved HL-1 cells and NCMs.

Starvation represents a unique biological situation, where activation of autophagy and apoptosis occur simultaneously. ${ }^{30}$ Therefore, predomination of autophagy (cell survival) over apoptosis (cell death) will result in a greater rate of cell survival or, in contrast, strong activation of an apoptotic signal will increase cell death. ${ }^{34}$ In our experimental model, we observed UA-8 significantly improved viability of both $\mathrm{HL}-1$ cells and NCMs following starvation. 

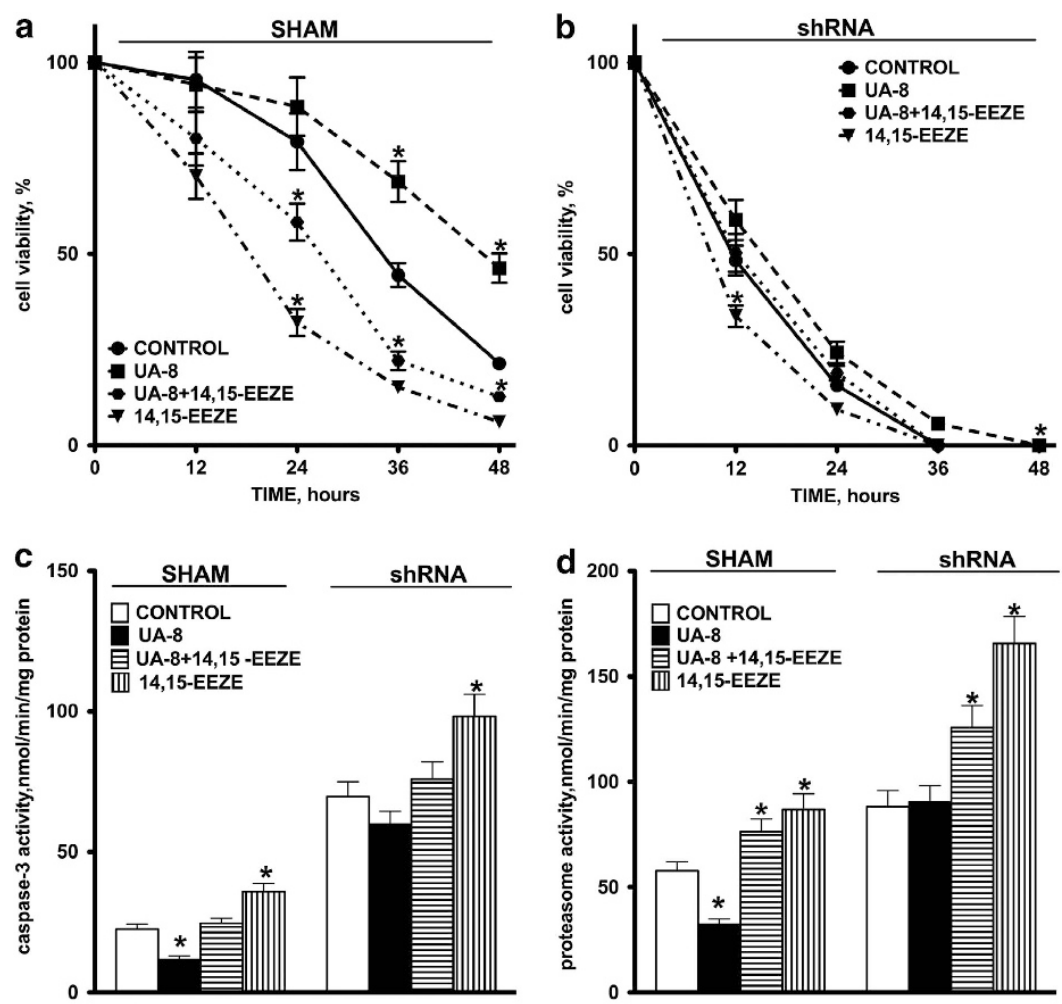

e

STARVATION
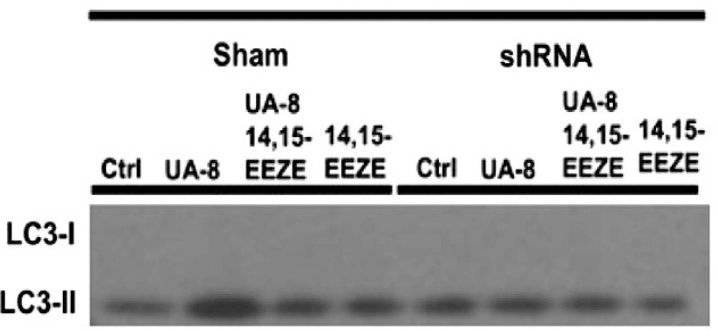

$\beta$-actin
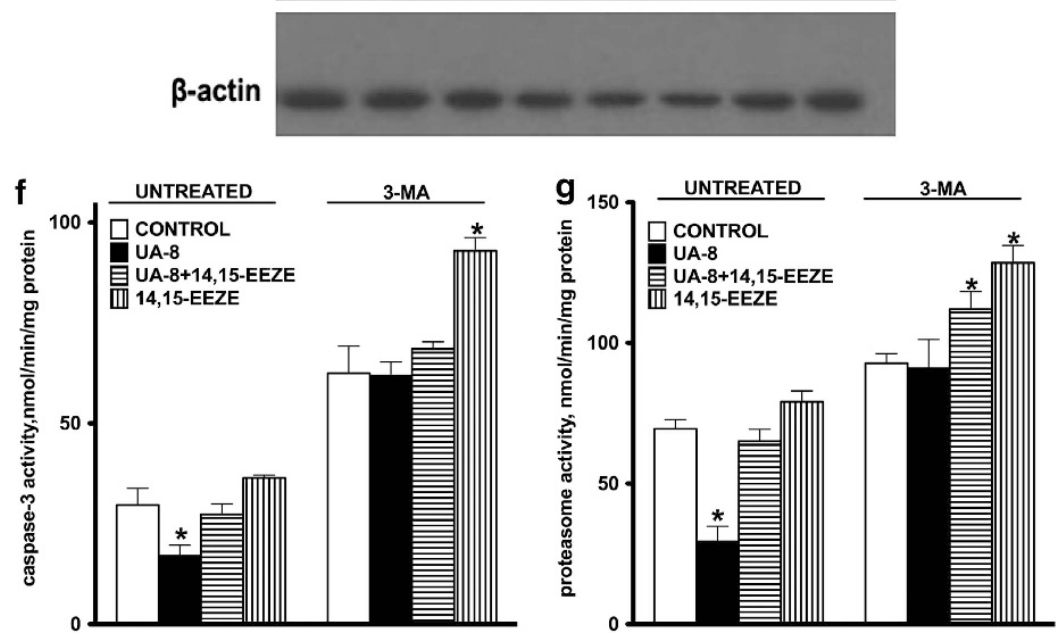

Figure 6 The effects of UA-8 are significantly abolished by genetic or pharmacological inhibition of the autophagic response. HL-1 cells were transfected with either shRNA to ATG7 or scrambled shRNA (Sham). (a, b) UA-8 $(1 \mu \mathrm{M})$ failed to prevent the loss in cell viability in ATG7-silenced HL-1 cells as compared to sham treated cells. Similarly, silencing of ATG7 prevented UA-8 from limiting increases in caspase-3 (c) and total proteasome activities (d) in starved HL-1 cells. (e) A representative western blot of LC3l and LC3-II expression after $24 \mathrm{~h}$ of starvation in sham and ATG7-silenced HL-1 cells showing 50-60\% reduction in UA-8 enhanced autophagy. (f $\mathbf{f}$ ) HL-1 cells were starved in the presence of 3-MA (5mM), a pharmacological inhibitor of autophagy, for $24 \mathrm{~h}$. 3-MA reduced the protective effects of UA-8 toward caspase-3 and total proteasome activities in starved HL-1 cells. Values are represented as mean \pm S.E.M., $N=3$. Significance was $P<0.05$, *significantly different from control 
HL-1
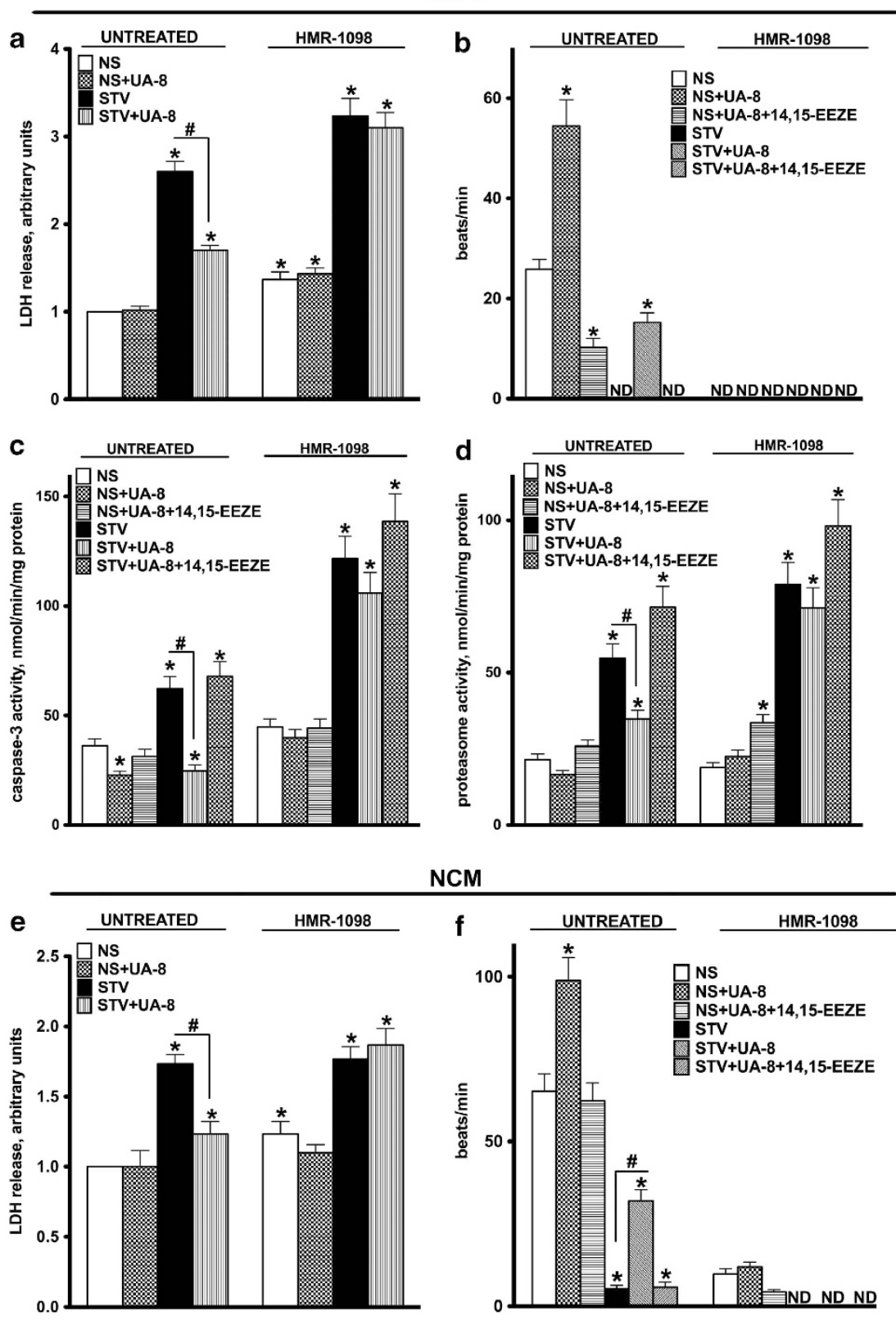

NCM
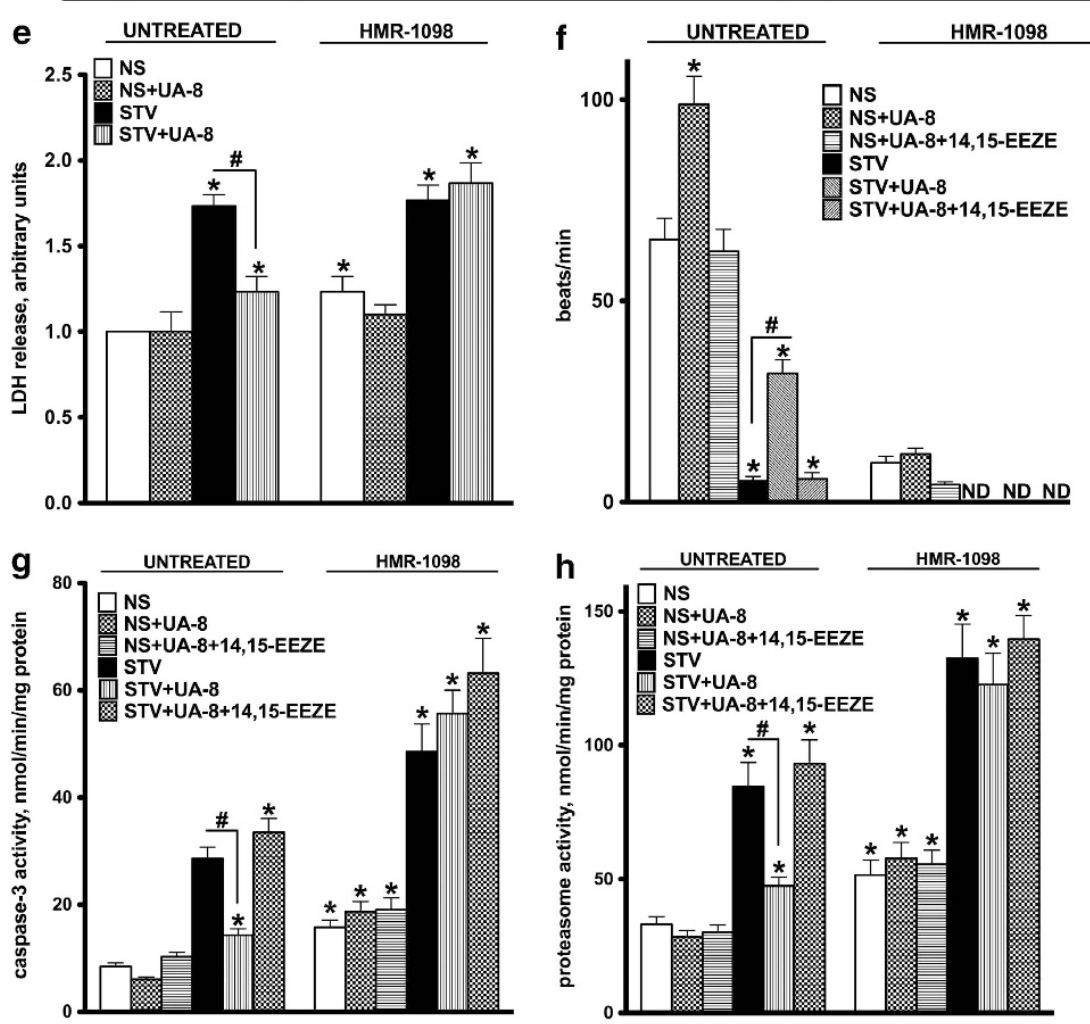
a

HL-1

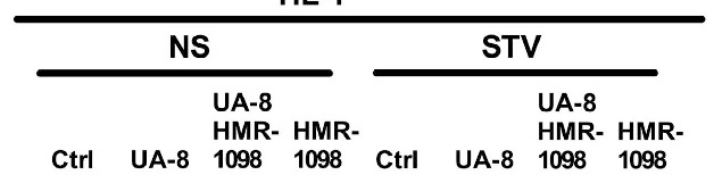
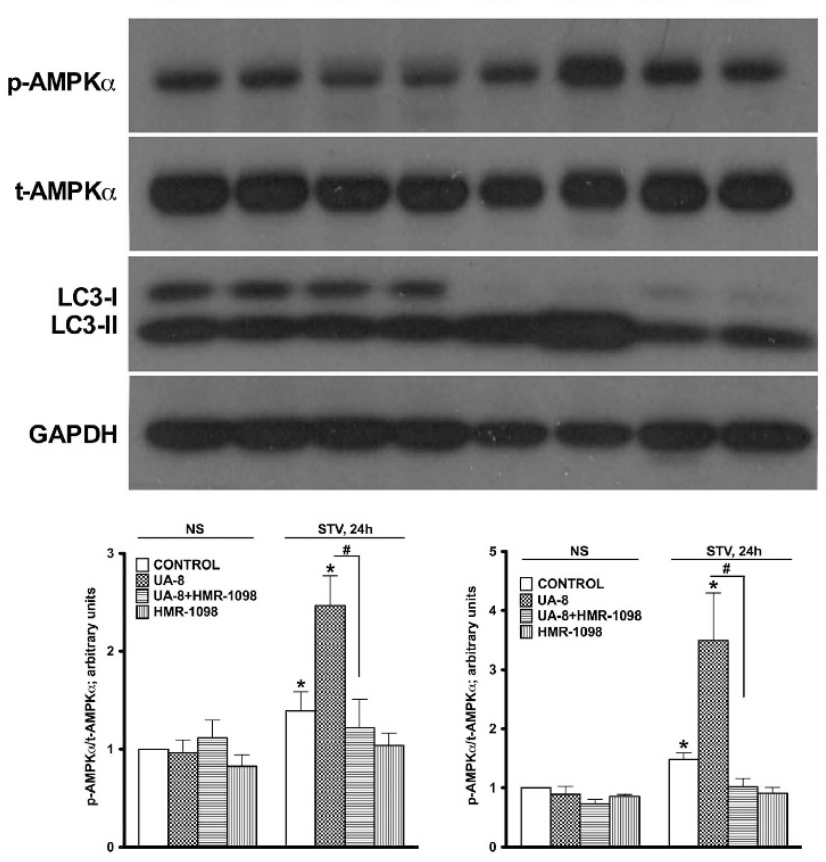

C

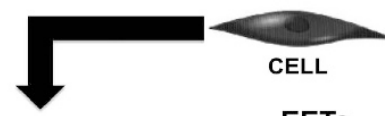

moderate stress

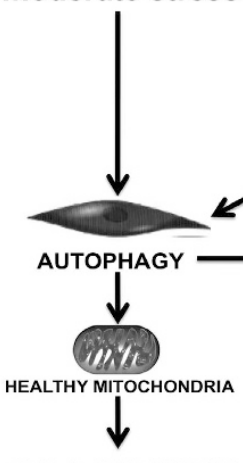

CELL SURVIVAL b
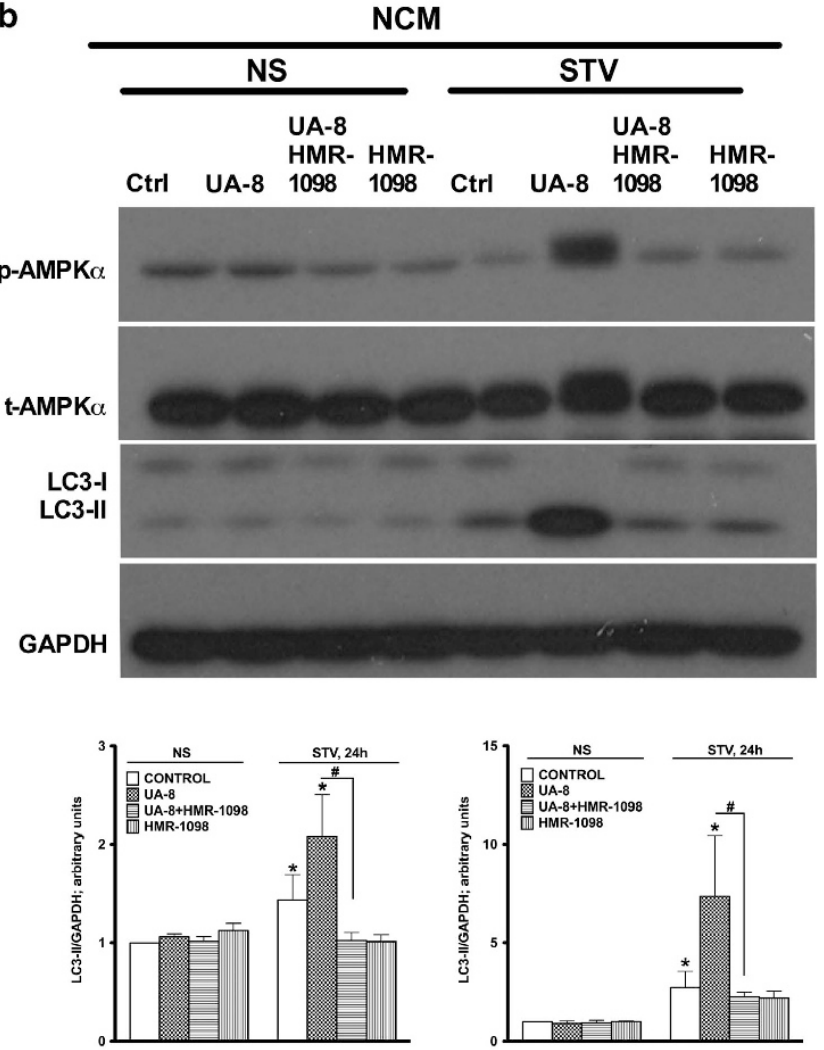

Figure 8 UA-8-triggered phosphorylation of AMPK and modulation of the autophagic response in starved HL-1 cells and NCMs were abolished by cotreatment with HMR-1098. The increased phosphorylated AMPK (Thr172) correlated with UA-8-activated autophagic response following $24 \mathrm{~h}$ of starvation in HL-1 cells (a) and NCMs (b), which was detected by western blot. The relative changes in phosphorylated AMPK and LC3-II expression levels were quantified in HL-1 cells and NCMs following treatments after $24 \mathrm{~h}$ of starvation and are presented below as respective representative western blots. Values are represented as mean \pm S.E.M., $N=3$. Significance was $P<0.05$, *significantly different from control nonstarvation, "significantly different from UA-8. (c) A general scheme illustrating a hypothesis for EET-mediated protective effects. Increased levels of EETs can shift cell death pathways from apoptotic and necrotic responses, which result in cell loss, to an autophagic pathway, resulting in cell survival. Autophagy may enhance turnover of damaged molecules and organelles, such as mitochondria, increasing survivability

Figure 7 Inhibition of $p m K_{\text {ATP }}$ channels abolished the protective effects of UA-8 in starved $\mathrm{HL}-1$ cells and NCMs. $\mathrm{HL}-1$ cells and NCMs were starved for $24 \mathrm{~h}$ in the presence of UA-8 $(1 \mu \mathrm{M})$ with or without HMR-1098 $(10 \mu \mathrm{M})$, a pharmacological inhibitor of $p m K_{\text {ATP }}$ channels. Treatment with UA-8 reduced release of LDH from starved HL-1 cells (a) and NCMs (e), indicative of increased cell survivability. HMR-1098 abolished stimulating effect of UA-8 on contractility of both HL-1 cells (b) and NCMs (f) under normal conditions and after $24 \mathrm{~h}$ of starvation. Inhibition of $p m K_{\text {ATP }}$ channels with HMR-1098 significantly abolished the ability of UA-8 to prevent activation of caspase-3 and proteasome activity in starved $\mathrm{HL}-1$ cells $(\mathbf{c}, \mathbf{d})$ and $\mathrm{NCMs}(\mathbf{g}, \mathbf{h})$. Values are represented as mean \pm S.E.M., $N=3$. Significance was $P<0.05$, ${ }^{*}$ significantly different from control nonstarvation, " significantly different from UA-8 treatment or statistically not different (ND) 
The protective effect was abolished by cotreatment with its antagonist 14,15-EEZE, suggesting the effects were EET specific, consistent with our previously published data. ${ }^{35}$ One of our key experiments demonstrated that UA-8 promoted greater colony formation of starved $\mathrm{HL}-1$ cells as compared with controls. Importantly, the colony formation ability (CFA) experiments started with the same number of cells and devoid of UA-8, suggesting that the EET-mediated protective effect occurred during the starvation period. This limitation of irreversible growth arrest suggests a proliferative capability of UA-8, consistent with evidence demonstrating EET-mediated procarcinogenic effects. ${ }^{14}$

Activation of degenerative processes has been described and attributed to detrimental consequences of prolonged starvation. ${ }^{30,36,37}$ Consistent with this evidence, starvation triggered a marked increase in caspase- 3 and total proteasome activities in both $\mathrm{HL}-1$ cells and NCMs. We show that UA-8 significantly attenuated caspase-3 and total proteasome activation. Activation of autophagy has been shown to favor cell survival and suppress cell death under various stress conditions. ${ }^{38-44}$ Although EETs are known to promote cell survival, ${ }^{45,46}$ there is remarkably little known regarding their role in regulating autophagic pathways. We show that EET-mediated events increase expression of LC3-II and formation of autophagosomes (morphological data) in starved $\mathrm{HL}-1$ cells. Furthermore, shRNA silencing of Atg7, an essential autophagic protein, abolished the protective effects of UA-8 and resulted in a significant decline in cardiac cell survival during starvation. The subsequent large increase in caspase-3 and proteasome activities, which occurred in cells where Atg7 was silenced, suggests there was a switch in cell death pathways from autophagy to apoptosis. Taken together, our data strongly suggest that EET-mediated protective events involve modulating an autophagic response that, in turn, promotes cell survival during starvation. Although the exact mechanism remains unknown and might potentially involve blocking the autophagic flux, we hypothesize that the protective effect involves activation of autophagy.

AMPK has a critical role in regulating cellular growth and metabolism, acting as a metabolic sensor, allowing adaptive responses to reduced energy. Upstream factors such as LKB1 and CaMKK $\beta\left(\mathrm{Ca}^{2+}\right.$ calmodulin-dependent protein kinase kinase- $\beta$ ) regulate AMPK activity under normal and stressed conditions, respectively. ${ }^{47}$ Activation of AMPK can trigger downstream signals, such as directly activating UNC-51-like kinase (ULK1) or inhibiting mammalian target of rapamycin complex 1 (mTORC1), which will induce an autophagic response. ${ }^{48}$ Indeed, increased AMPK activation correlated with the enhanced levels of LC3-II protein and an increased number of autophagosomes in UA-8-treated cells, which was attenuated with HMR-1098. We, and others, previously demonstrated that EET-mediated effects involve pmK $\mathrm{K}_{\text {ATP }}$ channels; however, it is unknown how these channels regulate autophagy or AMPK activation., $81,49,50$ Cardiac $p m K_{\text {ATP }}$ channels are known to be involved in regulating ionic homeostasis under conditions of metabolic stress and have demonstrated cardioprotective effects. ${ }^{26,33}$ The pmK $\mathrm{K}_{\text {ATP }}$ channels can be activated when cytoplasmic ATP is depleted, leading to shortening of action potential and reduced membrane depolarization, consequently reducing intracellular calcium overload. ${ }^{51}$ Currently, it remains unknown through which molecular mechanism(s) EETs target the autophagic response; our data clearly demonstrate that activation of $p m K_{\text {ATP }}$ channels and $\mathrm{AMPK}$ are required for EET-mediated events.

Collectively, our data strongly suggest a regulatory role for EETs in autophagic signaling that promotes cell survival. Interestingly, activation of AMPK has been shown to trigger removal of damaged mitochondria via ULK1-dependent mechanism and promotes biogenesis through PPAR- $\gamma$ coactivator-1 $\alpha$ (PCG-1 $\alpha$ )-dependent process, maintaining mitochondrial homeostasis following cellular stress. ${ }^{47} \mathrm{We}$ previously demonstrated that EETs preserve mitochondrial function and reduce damage to stress, improving cell survival and limiting tissue injury. ${ }^{7,35,46,52,53}$ Mitochondria play a crucial role in cell survival during unfavorable conditions, including starvation; as such, their preservation is an important physiological strategy orchestrating cell survival and sustainability. ${ }^{22,23}$ Our data demonstrated that mitochondrial content was preserved in starved cells following both control and UA-8 treatments. Importantly, the corresponding decline in mitochondrial function observed in controls was preserved by EET-mediated events. We speculate that the accumulation of mitochondrial protein content reflects the cell response to spare mitochondria from the degradation, whereas the other cytosolic constitutes remain vulnerable to be degraded via the autophagic machinery. We can conclude that the mitochondria found in UA-8 treated cells were healthier. We therefore hypothesize that EET-mediated events trigger protective mechanisms, which will sustain a healthier pool of mitochondria thus promoting cell survival. However, it remains unknown how EETs protect mitochondria in this model. Although we did not observe direct activation of mitophagy, we can infer that the EET-mediated protective mechanism(s) either promote the removal of damaged mitochondria or, alternatively, directly sustain mitochondrial function by enhancing the electron transport chain.

Thus, we hypothesize that EET-mediated events protect mitochondrial quality by regulating an autophagic response, preserving mitochondria and shifting the cell death pathway toward survival. Finely balanced autophagic machinery is important for proper function of terminally differentiated cardiomyocytes as loss of cardiomyocytes via apoptosis or necrosis would compromise cardiac function on the systemic level. In conclusion, we provide evidence that biological effects of eicosanoids are tightly interconnected with autophagy and the preservation of a pool of healthy mitochondria (Figure 8c). This interconnection might be involved in the pathogenesis of many diseases, and therefore can be considered as an attractive target for novel therapeutic interventions.

\section{Materials and Methods}

Cell cultures. HL-1 cardiac cells were a kind gift from Dr. Claycomb (New Orleans, LA, USA). Cells were cultivated in Claycomb media supplemented with glutamine and norephinephrine as previously described. ${ }^{54} \mathrm{HL}-1$ cells were maintained at $37^{\circ} \mathrm{C}$ in a humidified atmosphere of $5 \% \mathrm{CO}_{2}$ and $95 \%$ air. $\mathrm{NCMs}$ were isolated from 2- to 3-day-old rat pups as described before. ${ }^{55}$ Isolated cardiomyocytes were cultivated in DMEM media with $10 \%$ fetal bovine serum (FBS) at $37^{\circ} \mathrm{C}$ in humidified incubator maintaining $5 \% \mathrm{CO}_{2}$ and $95 \%$ air. Cell viability was assessed using Trypan blue exclusion as previously described. ${ }^{56}$ MTT assay was employed to estimate the total cellular metabolic activity based on the 
reduction of MTT by mitochondrial dehydrogenases. ${ }^{28}$ Activity of LDH released from injured cells was measured in cultivation medium based on conversion of MTT into formazan as previously described. ${ }^{57}$ Beating rate was estimated by counting the number of beats per min in five different cell clusters in five independently blinded experiments.

Treatment protocols. Starvation was modulated by incubation cells in amino acid and serum-free buffer as previously described. ${ }^{58}$ In this study, we utilized a novel EET analog UA-8 $(1 \mu \mathrm{M})$ that possesses EET-mimetic and sEH inhibitory properties. ${ }^{35}$ In order to block EET-mediated effects, we utilized the antagonist, 14,15-EEZE $(10 \mu \mathrm{M})$. Control experiments utilized 14,15-EET $(1 \mu \mathrm{M})$, with or without the sEH inhibitor trans-4-[4-(3-adamantan-1-y1-ureido)-cyclohexyloxy]-benzoic acid (tAUCB, $1 \mu \mathrm{M}$ ).

Colony formation assay. CFA was performed as previously described. ${ }^{59}$ Briefly, HL-1 cells were treated and starved for $24 \mathrm{~h}$, after which floating cells were harvested and plated $\left(1000 \mathrm{cells} / 1 \mathrm{~cm}^{2}\right)$ into normal drug-free Claycomb media for $72 \mathrm{~h}$. Cells were stained with $1 \%$ crystal violet for $30 \mathrm{~s}$ after fixation with $4 \%$ paraformaldehyde for $5 \mathrm{~min}$. The number of colonies formed, defined as $>50$ cells/colony, were counted.

Inhibition of autophagy. Silencing of Atg7 expression was achieved by transfection of HL-1 cells with plasmids expressing shRNA against the mouse Atg7 gene (OriGene Technologies, Rockville, MD, USA). Atg7-targeted shRNA and scrambled negative control were cloned into a pGFP-V-RS plasmid under a U6 promoter. Plasmids were amplified in the K-12 strain of Escherichia coli and then purified using the EndoFree plasmid purification kit (Qiagen, Valencia, CA, USA). Cells were transfected with Lipofectamine 2000 (Invitrogen, Carlsbad, CA, USA) in accordance with the manufacturer's instructions. Transfection efficiency with shRNA plasmids was determined qualitatively by the expression of green fluorescent protein (GFP). Cells were subjected to starvation $24 \mathrm{~h}$ after transfection, and the knockdown efficiency of the plasmids was assessed by immunoblotting. Control experiments were performed where 3-MA (Sigma-Aldrich, Oakville, ON, Canada) was dissolved in dimethyl sulfoxide (DMSO) and added to cardiac cells $(5 \mathrm{mM})$ for $24 \mathrm{~h}$ to inhibit autophagy.

Western blot assay and antibodies. HL-1 or NCMs were treated as described above, washed with ice-cold phosphate buffer saline (PBS) and harvested at different time points $(0,12,24,36$ and $48 \mathrm{~h})$ using ice-cold lysis buffer $(20 \mathrm{mM}$ Tris- $\mathrm{HCl}, 50 \mathrm{mM} \mathrm{NaCl}, 50 \mathrm{mM} \mathrm{NaF}, 5 \mathrm{mM}$ Na pyrophosphate, $0.25 \mathrm{M}$ sucrose, $1 \mathrm{mM}$ DTT, $1 \%$ Triton X-100 and protease/phosphatase inhibitors). Cell lysates were incubated on ice for $10 \mathrm{~min}$ and then centrifuged at $13000 \times g$ for $15 \mathrm{~min}\left(4^{\circ} \mathrm{C}\right)$. The Bradford assay was used to measure total protein content in supernatants. Then, $20 \mu \mathrm{g}$ of protein was resolved in $15 \% \mathrm{SDS}$ polyacrylamide gel and then transferred electrophoretically to polyvinylidene fluoride membranes that were then blocked with $5 \%$ non-fat milk in TBS-T buffer $(0.15 \mathrm{M} \mathrm{NaCl}, 3 \mathrm{mM} \mathrm{KCl}, 25 \mathrm{mM}$ tris hydroxymethyl methylamine and $0.1 \%$ tween$25, \mathrm{pH} 7.4$ ) for $1 \mathrm{~h}$ at room temperature. Membranes were washed three times with TBS-T buffer and then incubated overnight at $4{ }^{\circ} \mathrm{C}$ with anti-LC3 antibody (Cell Signaling Technology, Inc., New England Biolabs, Ltd., Whitby, ON, Canada) to detect both LC3-I and LC3-II. Membranes were washed as described above and incubated with horseradish peroxidase-linked anti-rabbit lgG secondary antibody (Invitrogen) for $2 \mathrm{~h}$ at room temperature, followed by washing as described above. Other antibodies utilized included AMPK $\alpha$ (Cell Signaling), Phospho-AMPK $\alpha$ (Thr172) (Cell Signaling), VDAC1 (Abcam, Burlingame, CA, USA), SDH-A (Cell Signaling), COX IV (Cell Signaling), $\beta$-actin (Cell Signaling) or GAPDH (Cell Signaling) antibodies. Chemiluminescence substrate reagents were used to detect signals. Relative band intensity to control was measured using Image J software ( $\mathrm{NIH}$, Bethesda, MD, USA). Immunocytochemistry (ICC) was used to detect autophagosomes using LC3 antibody (Cell Signaling) according to the manufacturer's instructions.

Assessment of mitochondrial respiratory chain enzymatic activities. Citrate synthase (CS), succinate dehydrogenase (SDH), and cytochrome $c$ oxidase (COX) were assayed spectrophotometrically in cell lysates as previously described. ${ }^{23}$ Assessments were repeated in three independent experiments and enzymatic activities were expressed as $\mathrm{nmol} / \mathrm{min}$ per $\mathrm{mg}$ protein.

Election microscopy. HL-1 cells were grown on glass bottom dishes (MatTek, Ashland, MA, USA) and underwent starvation treatment as described above for $24 \mathrm{~h}$. Cells were then rinsed with PBS and fixed with $2 \%$ paraformaldehyde and $2 \%$ glutaraldehyde in $0.1 \mathrm{M}$ sodium cacodylate for $30 \mathrm{~min}$. Cell monolayer was then post-fixed in $1 \%$ sodium tetroxide in $0.1 \mathrm{M}$ sodium cacodylate for $30 \mathrm{~min}$ on ice and in the dark. Then, $2 \%$ uranyl acetate was used for en-block staining of the samples for $30 \mathrm{~min}$ on ice and in the dark. Dehydration was done by increasing concentrations of ethanol (50-100\%). Finally, resin-filled beams were transferred upside-down on top of the cells and left at $60^{\circ} \mathrm{C}$ incubator for $48 \mathrm{~h}$ to polymerize. Imaging was done using Philips 410 electron microscope, using Megaview III soft imaging system and iTEM software (Olympus, Münster, Germany). Experiments were repeated three independent times.

Caspase-3 and 20S proteasome activity assays. Caspase-3 activity was assessed using a spectrofluorometric assay as described previously. ${ }^{60}$ Briefly, caspase-3 activity was determined in cytosolic fractions by monitoring the release of 7-amino-4-methylcoumarin (AMC) by proteolytic cleavage of the peptide Ac-DEVD-AMC (20 $\mu \mathrm{M}$; Sigma-Aldrich). Total proteasome activity assay was determined in cytosolic fractions monitoring the release of $\mathrm{AMC}$ by proteolytic cleavage of the peptide Suc-LLVY-AMC (CHEMICON, Inc., Billerica, MA, USA) by $20 S$ proteasomes. Fluorescence was monitored in both caspase- 3 and total proteasome assays at wavelengths of $380 \mathrm{~nm}$ (excitation) and $460 \mathrm{~nm}$ (emission). Specific activities were determined from a standard curve established with AMC.

Statistical analysis. Results are presented as means \pm S.E.M. Statistical analysis used ANOVA with a Bonferonni post hoc test; $P<0.05$ was considered statistically significant.

\section{Conflict of Interest}

JRF owns stock in Rendux Therapeutics, Inc., that is developing and commercializing EET agonists for a range of applications including antiinflammatory properties and organ protection.

Acknowledgements. NA is supported by Studentships from Saudi Arabian Embassy and King Saud University. HEE-S is recipient of Studentship Award from Alberta Innovates Health Solutions (AlHS). JMS received salary support from AlHS. PEL received salary support as an AlHS Senior Scholar and holds the Dr. Charles A. Allard Chair in Diabetes Research. JRF was supported by the Robert A. Welch Foundation (GL625910) and NIH GM31278. We thank Dr. Nasser Tahbaz from the TEM Facility, Department of Cell Biology, Faculty of Medicine and Dentistry, University of Alberta, for his assistance with the EM imaging. This work was supported by an operating grant from the Canadian Institutes of Health Research (JMS MOP115037).

1. Rosenthal MD, Rzigalinski BA, Blackmore PF, Franson RC. Cellular regulation of arachidonate mobilization and metabolism. Prostaglandins Leukot Essent Fatty Acids 1995; 52: 93-98

2. Roman RJ. P-450 metabolites of arachidonic acid in the control of cardiovascular function. Physiol Rev 2002; 82: 131-185.

3. Levick SP, Loch DC, Taylor SM, Janicki JS. Arachidonic acid metabolism as a potential mediator of cardiac fibrosis associated with inflammation. J Immunol 2007; 178: 641-646.

4. Kim IH, Morisseau C, Watanabe T, Hammock BD. Design, synthesis, and biological activity of 1,3-disubstituted ureas as potent inhibitors of the soluble epoxide hydrolase of increased water solubility. J Med Chem 2004; 47: 2110-2122.

5. Fang X, Kaduce TL, Weintraub NL, Harmon S, Teesch LM, Morisseau C et al. Pathways of epoxyeicosatrienoic acid metabolism in endothelial cells. Implications for the vascular effects of soluble epoxide hydrolase inhibition. J Biol Chem 2001; 276: 14867-14874.

6. Node K, Huo Y, Ruan X, Yang B, Spiecker M, Ley K et al. Anti-inflammatory properties of cytochrome P450 epoxygenase-derived eicosanoids. Science 1999; 285: 1276-1279.

7. Katragadda D, Batchu SN, Cho WJ, Chaudhary KR, Falck JR, Seubert JM. Epoxyeicosatrienoic acids limit damage to mitochondrial function following stress in cardiac cells. J Mol Cell Cardiol 2009; 46: 867-875.

8. Dhanasekaran A, Gruenloh SK, Buonaccorsi JN, Zhang R, Gross GJ, Falck JR et al. Multiple antiapoptotic targets of the PI3K/Akt survival pathway are activated by epoxyeicosatrienoic acids to protect cardiomyocytes from hypoxia/anoxia. Am J Physiol Heart Circ Physiol 2008; 294: H724-H735.

9. Gross ER, Hsu AK, Gross GJ. GSK3beta inhibition and K(ATP) channel opening mediate acute opioid-induced cardioprotection at reperfusion. Basic Res Cardiol 2007; 102: 341-349.

10. Imig JD. Epoxides and soluble epoxide hydrolase in cardiovascular physiology. Physiol Rev 2012; 92: 101-130. 
11. Batchu SN, Chaudhary KR, El-Sikhry H, Yang W, Light PE, Oudit GY et al. Role of PI3Kalpha and sarcolemmal ATP-sensitive potassium channels in epoxyeicosatrienoic acid mediated cardioprotection. J Mol Cell Cardiol 2012; 53: 43-52.

12. Lee HC, Lu T, Weintraub NL, VanRollins M, Spector AA, Shibata EF. Effects of epoxyeicosatrienoic acids on the cardiac sodium channels in isolated rat ventricular myocytes. J Physiol 1999; 519(Pt 1): 153-168.

13. Lu T, Hoshi T, Weintraub NL, Spector AA, Lee HC. Activation of ATP-sensitive $\mathrm{K}(+)$ channels by epoxyeicosatrienoic acids in rat cardiac ventricular myocytes. J Physiol 2001 537(Pt 3): 811-827.

14. Panigrahy D, Edin ML, Lee CR, Huang S, Bielenberg DR, Butterfield CE et al. Epoxyeicosanoids stimulate multiorgan metastasis and tumor dormancy escape in mice. J Clin Invest 2012; 122: 178-191.

15. Chen Y, Klionsky DJ. The regulation of autophagy - unanswered questions. J Cell Sci 2011; 124(Pt 2): 161-170.

16. Yen WL, Klionsky DJ. How to live long and prosper: autophagy, mitochondria, and aging. Physiology (Bethesda) 2008; 23: 248-262.

17. Huang J, Klionsky DJ. Autophagy and human disease. Cell Cycle 2007; 6: 1837-1849.

18. Wong A, Grubb DR, Cooley N, Luo J, Woodcock EA. Regulation of autophagy in cardiomyocytes by $\operatorname{Ins}(1,4,5) \mathrm{P}(3)$ and $\mathrm{IP}(3)$-receptors. J Mol Cell Cardiol 2012; 54: 19-24.

19. Terman A, Brunk UT. Autophagy in cardiac myocyte homeostasis, aging, and pathology. Cardiovasc Res 2005; 68: 355-365.

20. Lee J, Giordano S, Zhang J. Autophagy, mitochondria and oxidative stress: cross-talk and redox signalling. Biochem $J$ 2012; 441: 523-540.

21. Wang K, Klionsky DJ. Mitochondria removal by autophagy. Autophagy 2011; 7: 297-300.

22. Gomes LC, Di Benedetto G, Scorrano L. During autophagy mitochondria elongate, are spared from degradation and sustain cell viability. Nat Cell Biol 2011; 13: 589-598.

23. Spinazzi M, Casarin A, Pertegato V, Salviati L, Angelini C. Assessment of mitochondrial respiratory chain enzymatic activities on tissues and cultured cells. Nat Protoc 2012; 7 : 1235-1246.

24. Wang S, Song P, Zou MH. AMP-activated protein kinase, stress responses and cardiovascular diseases. Clin Sci (Lond) 2012; 122: 555-573.

25. Inoki K, Kim J, Guan KL. AMPK and mTOR in cellular energy homeostasis and drug targets. Annu Rev Pharmacol Toxicol 2012; 52: 381-400.

26. Suzuki M, Sasaki N, Miki T, Sakamoto N, Ohmoto-Sekine Y, Tamagawa M et al. Role of sarcolemmal K(ATP) channels in cardioprotection against ischemia/reperfusion injury in mice. J Clin Invest 2002; 109: 509-516.

27. Yin H, Zhou Y, Zhu M, Hou S, Li Z, Zhong H et al. Role of mitochondria in programmed cell death mediated by arachidonic acid-derived eicosanoids. Mitochondrion 2012; 13 209-224.

28. Wang P, Henning SM, Heber D. Limitations of MTT and MTS-based assays for measurement of antiproliferative activity of green tea polyphenols. PLOS One 2010; 5 e10202.

29. Nakai A, Yamaguchi O, Takeda T, Higuchi Y, Hikoso S, Taniike M et al. The role of autophagy in cardiomyocytes in the basal state and in response to hemodynamic stress. Nat Med 2007; 13: 619-624

30. Martinet W, De Meyer GR, Herman AG, Kockx MM. Amino acid deprivation induces both apoptosis and autophagy in murine C2C12 muscle cells. Biotechnol Lett 2005; 27: 1157-1163

31. Chaudhary KR, Abukhashim M, Hwang SH, Hammock BD, Seubert JM. Inhibition of soluble epoxide hydrolase by trans-4- [4-(3-adamantan-1-yl-ureido)-cyclohexyloxy]benzoic acid is protective against ischemia-reperfusion injury. J Cardiovasc Pharmacol 2010; 55: 67-73.

32. Mizushima N, Ohsumi $\mathrm{Y}$, Yoshimori T. Autophagosome formation in mammalian cells. Cell Struct Funct 2002; 27: 421-429.

33. Gumina RJ, Pucar D, Bast P, Hodgson DM, Kurtz CE, Dzeja PP et al. Knockout of Kir6.2 negates ischemic preconditioning-induced protection of myocardial energetics. Am J Physiol Heart Circ Physiol 2003; 284: H2106-H2113.

34. Esteve JM, Knecht E. Mechanisms of autophagy and apoptosis: recent developments in breast cancer cells. World J Biol Chem 2011; 2: 232-238.

35. Batchu SN, Lee SB, Qadhi RS, Chaudhary KR, El-Sikhry H, Kodela R et al. Cardioprotective effect of a dual acting epoxyeicosatrienoic acid analogue towards ischaemia reperfusion injury. Br J Pharmacol 2011; 162: 897-907.

36. Pires J, Curi R, Otton R. Induction of apoptosis in rat lymphocytes by starvation. Clin Sci (Lond) 2007; 112: 59-67.

37. Hong JH, Hur KC, Chung JM. Potentiation of early necrotic death of glucose-starved pheochromocytoma 12 cells by nerve growth factor. Mol Cells 2000; 10: 443-451.

38. Peponi E, Drakos E, Reyes G, Leventaki V, Rassidakis GZ, Medeiros LJ. Activation of mammalian target of rapamycin signaling promotes cell cycle progression and protects cells from apoptosis in mantle cell lymphoma. Am J Pathol 2006; 169: 2171-2180.
39. Morselli E, Galluzzi L, Kepp O, Criollo A, Maiuri MC, Tavernarakis N et al. Autophagy mediates pharmacological lifespan extension by spermidine and resveratrol. Aging (Albany NY) 2009; 1: 961-970.

40. Dosenko VE, Nagibin VS, Tumanovska LV, Moibenko AA. Protective effect of autophagy in anoxia-reoxygenation of isolated cardiomyocyte? Autophagy 2006; 2: 305-306.

41. Hansen M, Chandra A, Mitic LL, Onken B, Driscoll M, Kenyon C. A role for autophagy in the extension of lifespan by dietary restriction in C. elegans. PLoS Genet 2008; 4: e24

42. Bellodi C, Lidonnici MR, Hamilton A, Helgason GV, Soliera AR, Ronchetti M et al. Targeting autophagy potentiates tyrosine kinase inhibitor-induced cell death in Philadelphia chromosome-positive cells, including primary CML stem cells. J Clin Invest 2009; 119 1109-1123.

43. Ge PF, Zhang JZ, Wang XF, Meng FK, Li WC, Luan YX et al. Inhibition of autophagy induced by proteasome inhibition increases cell death in human SHG-44 glioma cells. Acta Pharmacol Sin 2009; 30: 1046-1052.

44. Rubinsztein DC, Codogno P, Levine B. Autophagy modulation as a potential therapeutic target for diverse diseases. Nat Rev Drug Discov 2012; 11: 709-730.

45. Ma J, Zhang L, Han W, Shen T, Ma C, Liu Y et al. Activation of JNK/c-Jun is required for the proliferation, survival, and angiogenesis induced by EET in pulmonary artery endothelia cells. J Lipid Res 2012; 53: 1093-1105.

46. Batchu SN, Lee SB, Samokhvalov V, Chaudhary KR, El-Sikhry H, Weldon SM et al. Novel soluble epoxide hydrolase inhibitor protects mitochondrial function following stress. Can J Physiol Pharmacol 2012; 90: 811-823.

47. Mihaylova MM, Shaw RJ. The AMPK signalling pathway coordinates cell growth autophagy and metabolism. Nat Cell Biol 2011; 13: 1016-1023.

48. Gwinn DM, Shackelford DB, Egan DF, Mihaylova MM, Mery A, Vasquez DS et al. AMPK phosphorylation of raptor mediates a metabolic checkpoint. Mol Cell 2008; 30: 214-226.

49. Gross GJ, Gauthier KM, Moore J, Falck JR, Hammock BD, Campbell WB et al. Effects of the selective EET antagonist, 14,15-EEZE, on cardioprotection produced by exogenous or endogenous EETs in the canine heart. Am J Physiol Heart Circ Physiol 2008; 294 $\mathrm{H} 2838-\mathrm{H} 2844$

50. Lu T, Hong MP, Lee HC. Molecular determinants of cardiac K(ATP) channel activation by epoxyeicosatrienoic acids. J Biol Chem 2005; 280: 19097-19104.

51. Yao Z, Cavero I, Gross GJ. Activation of cardiac KATP channels: an endogenous protective mechanism during repetitive ischemia. Am J Physiol 1993; 264(2 Pt 2): $\mathrm{H} 495-\mathrm{H} 504$.

52. Chaudhary KR, El-Sikhry H, Seubert JM. Mitochondria and the aging heart. $J$ Geriatr Cardiol 2011; 8: 159-167.

53. El-Sikhry HE, Miller GG, Madiyalakan MR, Seubert JM. Sonodynamic and photodynamic mechanisms of action of the novel hypocrellin sonosensitizer, SL017: mitochondria cell death is attenuated by 11, 12-epoxyeicosatrienoic acid. Invest New Drugs 2011; 29 : $1328-1336$.

54. Claycomb WC, Lanson NA Jr, Stallworth BS, Egeland DB, Delcarpio JB, Bahinski A et al. $\mathrm{HL}-1$ cells: a cardiac muscle cell line that contracts and retains phenotypic characteristics of the adult cardiomyocyte. Proc Natl Acad Sci US 1998; 95: 2979-2984.

55. Samokhvalov V, Ussher JR, Fillmore N, Armstrong IK, Keung W, Moroz D et al. Inhibition of malonyl $\mathrm{CoA}$ decarboxylase reduces the inflammatory response associated with insulin resistance. Am J Physiol Endocrinol Metab 2012; 303: E1459-E1468.

56. Uliasz TF, Hewett SJ. A microtiter trypan blue absorbance assay for the quantitative determination of excitotoxic neuronal injury in cell culture. J Neurosci Methods 2000; 100 157-163.

57. Abe K, Matsuki N. Measurement of cellular 3-(4,5-dimethylthiazol-2-yl)-2,5-diphenyltetrazolium bromide (MTT) reduction activity and lactate dehydrogenase release using MTT. Neurosci Res 2000; 38: 325-329.

58. Brady NR, Hamacher-Brady A, Yuan H, Gottlieb RA. The autophagic response to nutrient deprivation in the $\mathrm{hl}-1$ cardiac myocyte is modulated by $\mathrm{Bcl}-2$ and sarco/endoplasmic reticulum calcium stores. FEBS J 2007; 274: 3184-3197.

59. Lucchinetti E, Awad AE, Rahman M, Feng J, Lou PH, Zhang L et al. Antiproliferative effects of local anesthetics on mesenchymal stem cells: potential implications for tumor spreading and wound healing. Anesthesiology 2012; 116: 841-856.

60. Seubert JM, Darmon AJ, El-Kadi AO, D'Souza SJ, Bend JR. Apoptosis in murine hepatoma hepa 1c1c7 wild-type, C12, and C4 cells mediated by bilirubin. Mol Pharmacol 2002; 62 257-264.

(1) () $\odot$ Cell Death and Disease is an open-access journal published by Nature Publishing Group. This work is licensed under a Creative Commons Attribution-NonCommercialNoDerivs 3.0 Unported License. To view a copy of this license, visit http://creativecommons.org/licenses/by-nc-nd/3.0/ 